\title{
Spontaneous Activity of Solitary Dopaminergic Cells of the Retina
}

\author{
Andreas Feigenspan, Stefano Gustincich, Bruce P. Bean, and Elio Raviola \\ Department of Neurobiology, Harvard Medical School, Boston, Massachusetts 02115
}

Dopaminergic interplexiform amacrine cells were labeled in transgenic mice with human placental alkaline phosphatase and could therefore be identified after dissociation of the retina and used for whole-cell current and voltage clamp. In absence of synaptic inputs, dopaminergic amacrines spontaneously fired action potentials in a rhythmic pattern. This activity was remarkably robust in the face of inhibition of various voltagedependent ion channels. It was minimally affected by external cesium or cobalt, suggesting no involvement of either the hyperpolarization-activated cation current $I_{\mathrm{h}}$ or voltagedependent calcium channels. Inhibiting calcium-activated potassium channels by charybdotoxin or tetraethylammonium slowed the repolarizing phase of the action potentials and eliminated a slow afterhyperpolarization but had a scarce effect on the frequency of spontaneous firing. Voltage-clamp experiments showed that the interspike depolarization leading to threshold results from tetrodotoxin-sensitive sodium channels active at the interspike voltages of -60 to $-40 \mathrm{mV}$. Because dopamine acts on distant targets in the retina, the pacemaker activity of dopaminergic amacrines may be necessary to ensure a tonic release of the modulator from their dendritic tree. Pacemaking is a property that this type of retinal amacrine cell shares with the dopaminergic mesencephalic neurons, but the ionic mechanisms responsible for the spontaneous firing are apparently different.

Key words: dopamine; retina; interplexiform amacrine cells; patch clamp; pacemaker activity; ion channels; subthreshold sodium current
Dopamine subserves fundamental functions in the nervous system: it facilitates and controls initiation of movement (Hikosaka and Wurtz, 1983), regulates reward behaviors and affective states (Le Moal and Simon, 1991), and, in the retina, is responsible for many of the events that lead to neural adaptation to light (Witkovsky and Dearry, 1991; Djamgoz and Wagner, 1992). Thus, an understanding of the mechanisms that control the release of this modulator may have important consequences for interventions in motor and affective disorders. An interesting property of the midbrain dopaminergic neurons is their capacity to generate action potentials in a rhythmic manner even in the absence of synaptic inputs (Grace and Onn, 1989; Lacey et al., 1989; Hainsworth et al., 1991; Yung et al., 1991; Cardozo, 1993; Cardozo and Bean, 1995). We have found that also dopaminergic amacrine cells spontaneously generate action potentials when isolated from the retina and studied in vitro (Gustincich et al., 1997). In this paper we show that these cells possess a pacemaker activity very similar to that of their counterparts in the midbrain (Grace and Bunney, 1983a,b; Grace and Onn, 1989; Yung et al., 1991). However, an analysis of the mechanism of spontaneous firing showed that, in contrast to the midbrain neurons, neither the hyperpolarization-activated cation current $I_{\mathrm{h}}$ nor voltagedependent calcium currents play a role in the firing of the dopaminergic amacrines: in these cells, the slow depolarization between spikes appears to result solely from tetrodotoxin-sensitive

\footnotetext{
Received Feb. 18, 1998; revised May 18, 1998; accepted June 10, 1998.

This work was supported by National Institutes of Health Grants EY01344 (E.R.) and NS36855 (B.P.B.) and by a McKnight Senior Investigator Award to E.R. A.F. and S.G. were supported by European Molecular Biology Fellowships. We thank Dr. R. C. Reid for help with the analysis of interspike intervals, Dr. I. M. Raman and A. Taddese for discussions, and H. M. Regan for technical assistance.

Correspondence should be addressed to Dr. Elio Raviola, Department of Neurobiology, Harvard Medical School, 220 Longwood Avenue, Boston, MA 02115.

Dr. Feigenspan's present address: Carl von Ossietzky Universität Oldenburg, Ammerländer Heerstraße 114-118, D-26111 Oldenburg, Germany.

Copyright (C) 1998 Society for Neuroscience $\quad 0270-6474 / 98 / 186776-14 \$ 05.00 / 0$
}

sodium channels. The fact that projection neurons with long axons directed to distant regions of the brain and a retinal interneuron share the property of spontaneous firing suggests that tonic dopamine release may be a common functional characteristic of dopaminergic neurons throughout the nervous system.

\section{MATERIALS AND METHODS}

Dissociation of the retina and identification of dopaminergic amacrine cells. For this study, a transgenic mouse line was used in which dopaminergic neurons in the retina and CNS express human placental alkaline phosphatase (PLAP) on the outer surface of the cell membrane (Gustincich et al., 1997). These animals were obtained by introducing into the mouse genome PLAP cDNA (Kam et al., 1985), linked to a promoter sequence of the gene for tyrosine hydroxylase (TH) (Banerjee et al., 1992), the rate-limiting enzyme for dopamine biosynthesis. Animals were anesthetized by intraperitoneal injection of $0.1 \mathrm{ml}$ of a solution containing 50 $\mathrm{mg} / \mathrm{ml}$ ketamine $\mathrm{HCl}$ (Ketaset; Fort Dodge Laboratories, Fort Dodge, IA) and $1 \%$ xylazine (Rompun; Bayer, Shawnee Mission, KS). After dissociation of the adult retina and plating of the cell suspension, solitary dopaminergic amacrines could be identified for recordings by labeling of their membrane by a monoclonal antibody to PLAP (E6; De Waele et al., 1982) conjugated to the fluorochrome $\mathrm{Cy} 3$ (E6-Cy3). The procedure of dissociation of the retina was described elsewhere (Gustincich et al., 1997): briefly, after removal of cornea, lens, and vitreous body, the eyecups including the retinas were transferred to a solution containing 20 $\mathrm{U} / \mathrm{ml}$ papain and $200 \mathrm{U} / \mathrm{ml}$ DNase I (both from Worthington, Freehold, NJ) in Earle's balanced salt solution (EBSS; Sigma, St. Louis, MO). At the end of the digestion $\left(45 \mathrm{~min}, 37^{\circ} \mathrm{C}\right)$, the eyecups were washed in a solution to stop papain activity $\left(5 \mathrm{~min}, 37^{\circ} \mathrm{C}\right)$. This solution contained 1 $\mathrm{mg} / \mathrm{ml}$ ovomucoid (Worthington), $1 \mathrm{mg} / \mathrm{ml}$ bovine serum albumin (Sig$\mathrm{ma}$ ), and $100 \mathrm{U} / \mathrm{ml}$ DNase I in EBSS. Then, the retinal pieces were carefully detached from the pigment epithelium and triturated using fire-polished Pasteur pipettes of varying bores. The resulting cell suspension was centrifuged at $1000 \mathrm{rpm}$ for $5 \mathrm{~min}$, and the pellet was resuspended in Minimum Essential Medium (Sigma) containing E6-Cy3 $(1: 100)$ and $0.1 \%$ bovine serum albumin. The dissociated retinal neurons were directly plated on the glass bottom of concanavalin A-coated $(1 \mathrm{mg} / \mathrm{ml})$ recording chambers and kept at $37^{\circ} \mathrm{C}$ in $5 \% \mathrm{CO}_{2}$ and $95 \% \mathrm{O}_{2}$ for at least $1 \mathrm{hr}$ before commencement of recordings. To prove that the cells stained by E6-Cy3 contained TH mRNA, nested RT-PCR was performed on single fluorescent cells isolated by suction with a patch- 


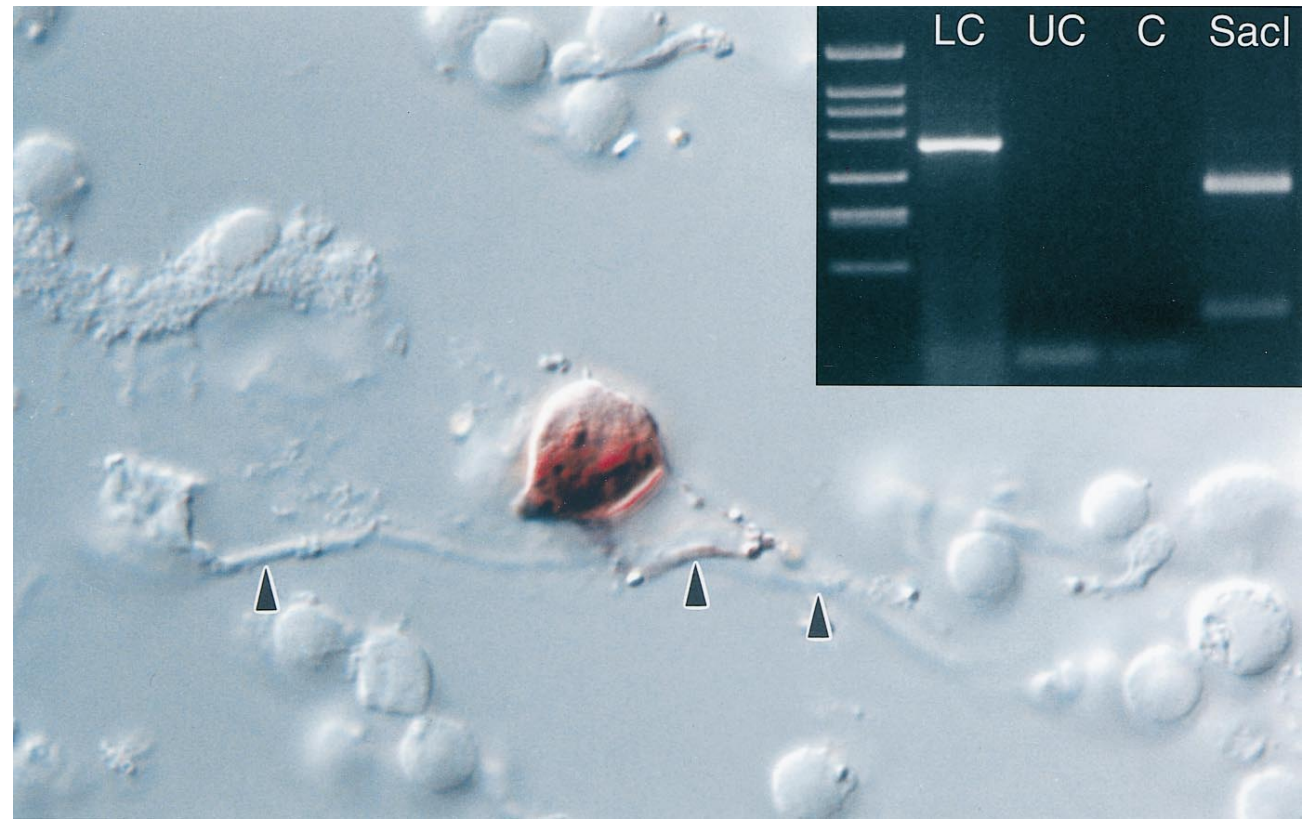

Figure 1. Solitary dopaminergic amacrine cell. After papain digestion and mechanical trituration of the retina, a formaldehyde-fixed dopaminergic amacrine was identified because it was stained by the histochemical method for PLAP (Gustineich et al., 1997). The dendrites (arrowheads) are mostly out of focus. Magnification, $800 \times$. Inset, Agarose gel electrophoresis of the cDNA fragments obtained after nested singlecell RT-PCR for TH transcript. The 360 bp product specific for TH mRNA was only amplified from a dopaminergic amacrine labeled by E6-Cy3 $(L C)$. An unstained cell $(U C)$ and a control reaction (C) were negative for TH. An aliquot of the reaction products from $\mathrm{LC}$ was purified and cut with $\mathrm{SacI}$ to show the specificity of the amplification. As expected, the digestion with this restriction enzyme produced fragments of 271 and $89 \mathrm{bp}$.

clamp pipette. The first-round forward (THF) primer was CTGGCCTTCCGTGTGTTTCAGTG, which hybridizes with TH cDNA at nucleotide (nt) 915 (GenBank accession number M69200), and the corresponding reverse (THR) primer was CCGGCTGGTAGGTTTGATCTTGG, which hybridizes with TH cDNA at nt 1296. The firstround RT-PCR product was 382 bp long. The second-round nested THF primer was AGTGCACACAGTACATCCGTCAT, which hybridizes with TH cDNA at nt 934, and the corresponding nested THR primer was GCTGGTAGGTTTGATCTTGGTA, which hybridizes with TH cDNA at nt 1293 . The final nested RT-PCR product was $360 \mathrm{bp}$ long. This fragment contained a unique $S a c$ I site, and digestion with this enzyme produced fragments of 271 and $89 \mathrm{bp}$. Further details of the procedure will be described in another paper.

Electrophysiology. For recordings, Petri dishes with the dissociated retinal cells were mounted on the stage of an inverted microscope (Diaphot 300, Nikon), and E6-Cy3-stained dopaminergic amacrines were identified by scanning the coverslip in epifluorescence. Patch-clamp recordings in the voltage- and current-clamp mode were performed with an Axopatch 200A amplifier (Axon Instruments, Foster City, CA). Currents were low-pass-filtered at $5 \mathrm{kHz}$ using the internal Bessel filter of the amplifier. Current and voltage outputs from the patch-clamp amplifier were digitized with a DigiData 1200 interface (Axon Instruments) and viewed with an oscilloscope (BK Precision, Chicago, IL) or directly on the screen of a Gateway 4DX2-66 computer. The sample frequency was $10-50 \mathrm{kHz}$ for whole-cell voltage-clamp recordings and $2-5 \mathrm{kHz}$ for current-clamp recordings. Fast current events recorded in the cellattached mode were sampled at a frequency of $5 \mathrm{kHz}$. Patch pipettes were constructed from borosilicate glass $(1.65 \mathrm{~mm}$ outer diameter, 1.2 $\mathrm{mm}$ inner diameter; A-M Systems, Everett, WA) using a horizontal two-stage electrode puller (BB-CH; Mecanex, Geneva, Switzerland); the electrode resistance ranged from 5 to $7 \mathrm{M} \Omega$. Electrodes were connected to the amplifier via an $\mathrm{Ag}-\mathrm{AgCl}$ wire. The electrode holder and the head stage were mounted on a piezoelectric, remote-controlled device attached to a three-dimensional micromanipulator (Burleigh Instruments, Fishers, NY). In voltage-clamp experiments, the series resistance of the pipettes was in the range of $12-20 \mathrm{M} \Omega$ and could be compensated up to $80 \%$ after cancellation of capacitive transients. Drugs were applied to single cells in the extracellular bath solution by gravity flow through an array of microcapillary tubes. Drugs could be selected using a Teflon rotary valve (Rheodyne, Cotati, CA). This application system allowed for a complete solution exchange in the vicinity of the recorded cell within 200-500 msec.

Recording solutions. Unless noted otherwise, the extracellular bath solution for recordings in current-clamp mode contained (in mM): 137 $\mathrm{NaCl}, 5.4 \mathrm{KCl}, 1.8 \mathrm{CaCl}_{2}, 1 \mathrm{MgCl}_{2}, 5 \mathrm{HEPES}$, and 10 glucose. The intracellular solution for recordings in current-clamp mode contained (in $\mathrm{mM}$ ): $125 \mathrm{~K}$-gluconate, $10 \mathrm{KCl}, 0.5 \mathrm{EGTA}$, and $10 \mathrm{HEPES}$. Recordings of voltage-dependent calcium currents were performed with the following extracellular solution (in mM): 145 TEACl, $20 \mathrm{CaCl}_{2}$, and 10 HEPES. The intracellular solution for these experiments contained (in mM): 117 TEACl, $4.5 \mathrm{MgCl}_{2}$, 9 EGTA, 9 HEPES, 14 phosphocreatine, $4 \mathrm{Mg}$-ATP, and $0.3 \mathrm{Na}$-GTP. The extracellular solution for voltageclamp recordings of sodium currents contained (in $\mathrm{mm}$ ): $100 \mathrm{NaCl}, 60$ TEACl, $2 \mathrm{CaCl}_{2}, 0.3 \mathrm{CdCl}_{2}$, and $10 \mathrm{HEPES}$, and the corresponding intracellular solution contained (in mM): $120 \mathrm{CsCl}, 20 \mathrm{TEACl}, 1 \mathrm{CaCl}_{2}$, $2 \mathrm{MgCl}_{2}, 11$ EGTA, and $10 \mathrm{HEPES}$. All biochemicals were obtained from Sigma unless otherwise noted. Stock solutions of apamin and charybdotoxin (Alomone Laboratories, Jerusalem, Israel) were stored at $-20^{\circ} \mathrm{C}$ and diluted in extracellular solution immediately before use. A stock solution of tetrodotoxin (TTX; Research Biochemicals, Natick, MA) was made in $2 \mathrm{~mm}$ citric acid and stored at $-20^{\circ} \mathrm{C}$. ATP, GTP, and phosphocreatine were prepared as a $10 \times$ stock solution and kept frozen at $-80^{\circ} \mathrm{C}$.

\section{RESULTS}

\section{Identification of dopaminergic amacrine cells}

As shown previously (Gustincich et al., 1997), two classes of amacrine cells express PLAP in the retina of our transgenic mice; one class is characterized by a large, spherical perikaryon that is stained by antibodies to TH and sends processes to the outer plexiform layer. This cell corresponds to type 1 dopaminergic (interplexiform) amacrine cells of other mammalian species (Mariani and Hokoc, 1988; Nguyen-Legros, 1988; Tauchi et al., 1990; Versaux-Botteri et al., 1984). Cells of the other class have a smaller perikaryon and do not exhibit $\mathrm{TH}$-like immunoreactivity. They correspond to the type 2 or small catecholaminergic amacrines of other mammals (Mariani and Hokoc, 1988; NguyenLegros, 1988; type 3 in the rabbit, according to Tauchi et al., 1990). After dissociation of the retina, type 1 dopaminergic amacrines are easily recognized because of the large size and intense staining with both the histochemical method for PLAP (Fig. 1) and the monoclonal antibody to PLAP E6-Cy3. Small type 2 cells are seen only with difficulty.

Nested single-cell RT-PCR confirmed beyond doubt that the large neurons stained by E6-Cy3 contained TH mRNA and, therefore, were dopaminergic amacrines, because TH transcript was absent in unlabeled cells (Fig. 1, inset).

Previous experiments had demonstrated that the physiological 

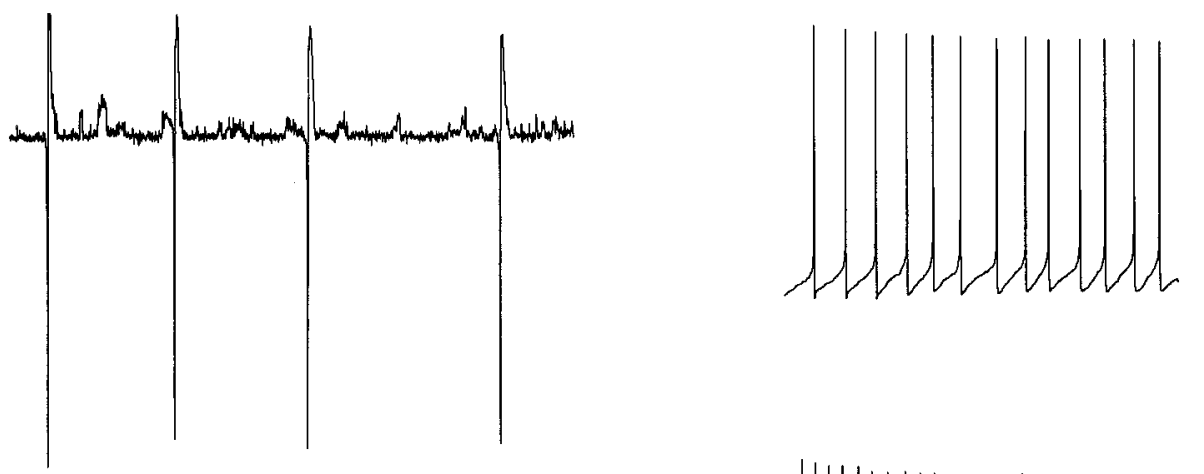

\section{$2 \mathrm{pA}$}

$10 \mathrm{pA}$

$100 \mathrm{~ms}$
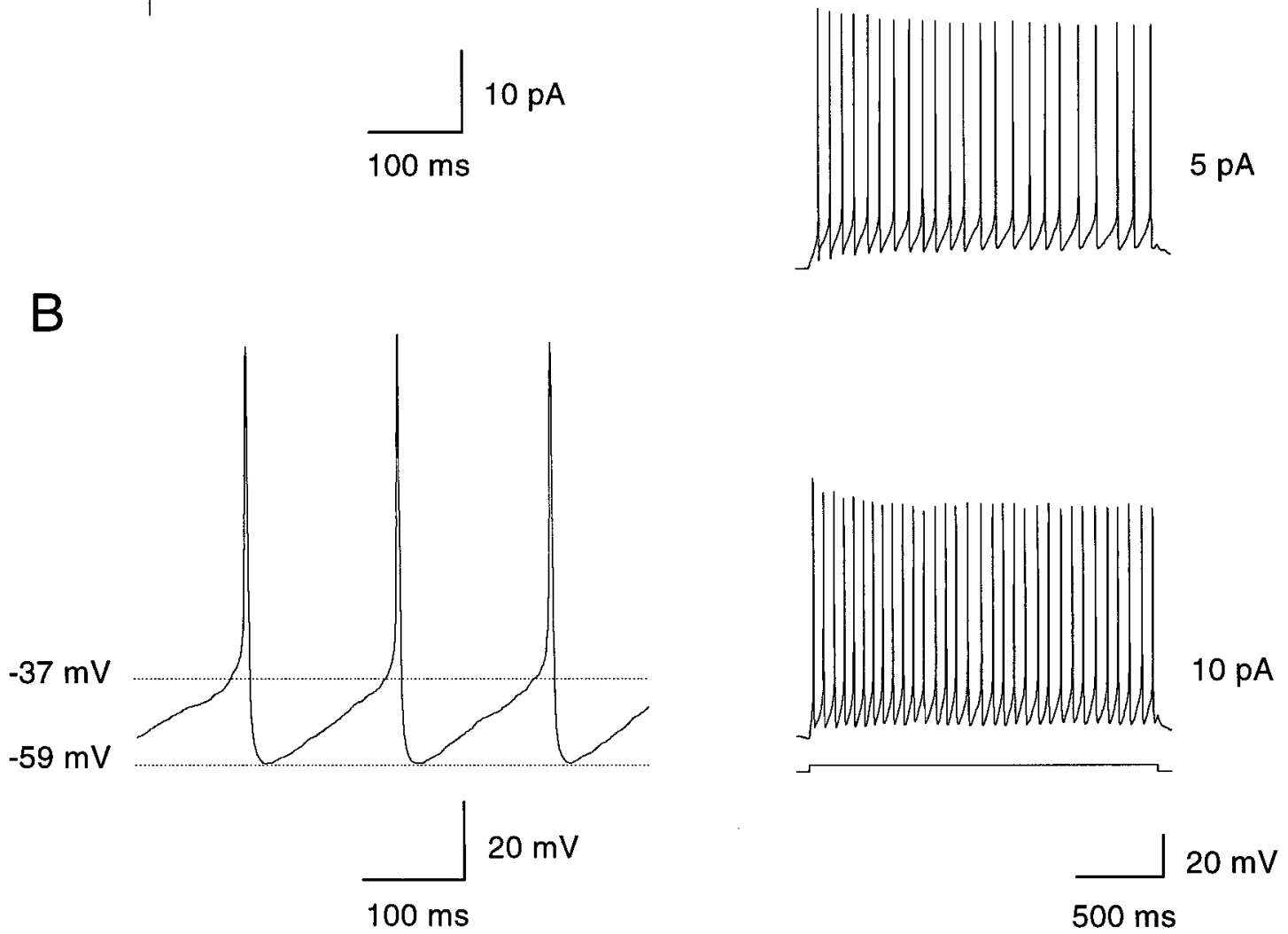

Figure 2. Spontaneous and depolarization-induced activity of solitary dopaminergic amacrines. $A$, Action currents observed in the cell-attached configuration with the pipette potential held at $0 \mathrm{mV}$. Single-channel events, probably attributable to opening of potassium channels, were also visible. $B$, Spontaneous activity of a solitary dopaminergic amacrine measured in whole-cell current clamp with no current applied. The amplitude of the spikes was $89 \mathrm{mV}$ (measured from the threshold at $-37 \mathrm{mV}$ ); their width at threshold was $4.3 \mathrm{msec}$. The spikes were followed by a prolonged afterhyperpolarization that peaked at $-59 \mathrm{mV}$. C, In current clamp, a dopaminergic amacrine was hyperpolarized to $-50 \mathrm{mV}$ to remove spontaneous activity. The membrane potential was then gradually increased by injecting depolarizing current steps ( $2 \mathrm{sec}$ each). The dopaminergic amacrine followed the current injections by linearly increasing its spike frequency. With depolarizations $>20 \mathrm{pA}$, dopaminergic amacrines fired a burst of three to five action potentials followed by a depolarizing block.

responses of dopaminergic amacrines were not altered by expression of PLAP at the cell surface and binding of antibody to the enzyme (Gustincich et al., 1997).

\section{Spontaneous activity}

Recordings with the patch-clamp technique in the whole-cell configuration were obtained from 250 dopaminergic amacrines. Cells were chosen that possessed two or three dendrites that could be followed for a length of at least $30 \mu \mathrm{m}$ (Fig. 1). Stable patch-clamp recordings, lasting from 10 to $45 \mathrm{~min}$, were obtained from $62 \%$ of the cells. Dopaminergic amacrines were spontaneously active. In the cell-attached configuration, action currents were recorded across the patch, usually in a rhythmic pattern (Fig. $2 A$ ). After disruption of the patch membrane, $\sim 80 \%$ of the cells continued to fire spontaneous action potentials (recording in current-clamp mode with no injected current). The frequency of firing was $3-9 \mathrm{~Hz}[6.0 \pm 0.5(\mathrm{SEM}) \mathrm{Hz} ; n=25]$, the same rate as that of the action currents recorded in the cell-attached configuration (Fig. $2 B$ ). Interspike intervals were relatively constant in 
A

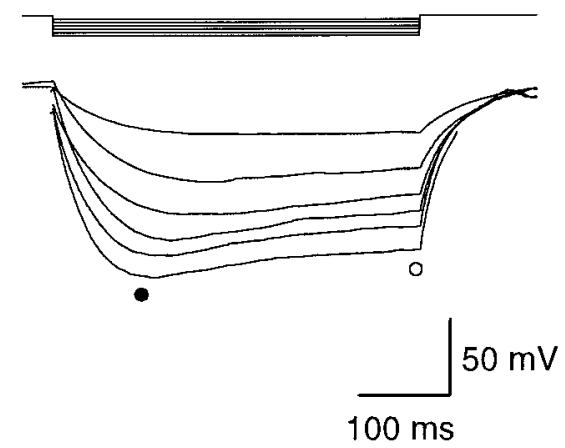

C

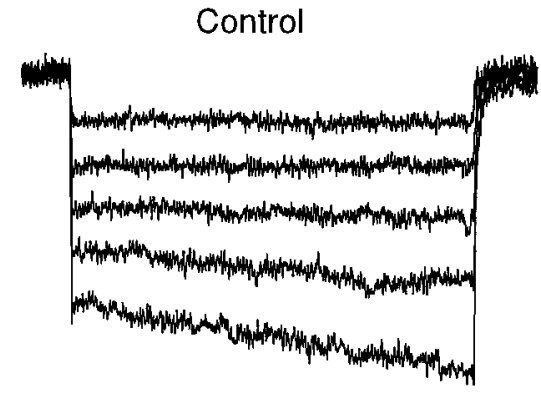

B

1 (pA)

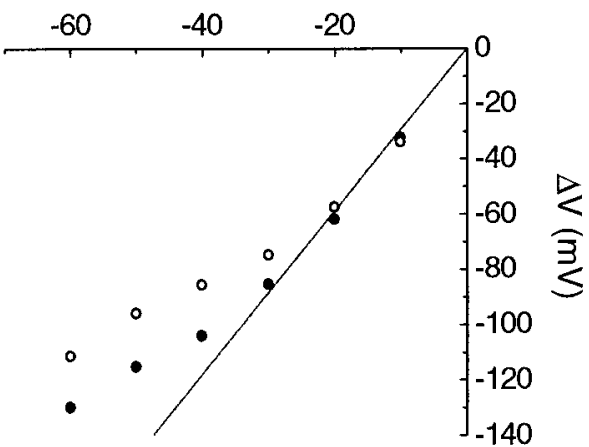

$E$

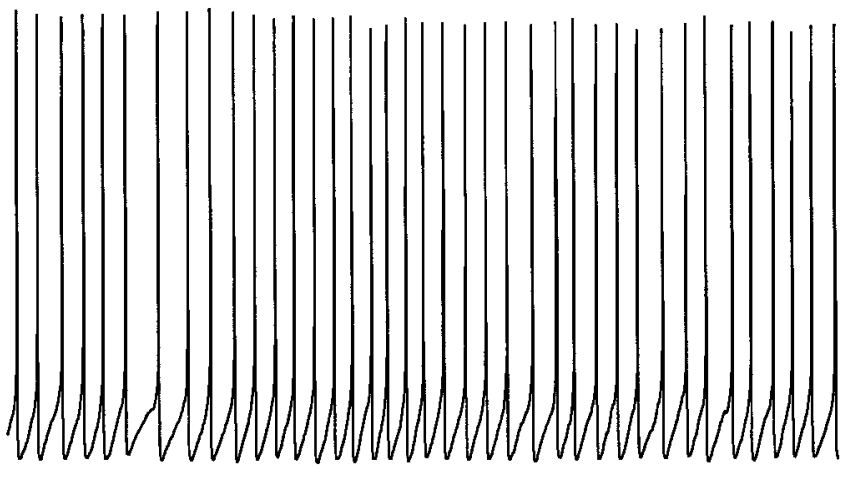

$1 \mathrm{mM} \mathrm{Cs}^{+}$

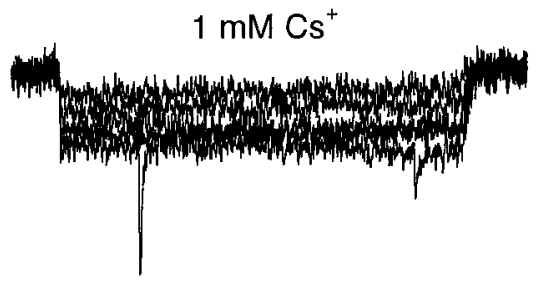

$10 \mathrm{pA}$

$250 \mathrm{~ms}$

$20 \mathrm{mV}$

$500 \mathrm{~ms}$

Figure 3. Input resistance and hyperpolarization-activated currents of dopaminergic amacrines. $A$, Input resistance measurements. To suppress spontaneous activity, a dopaminergic amacrine was hyperpolarized to $-54 \mathrm{mV}$. Voltage responses to negative current pulses $(6$ steps of $-10 \mathrm{pA}$ each, $400 \mathrm{msec}$ duration) were measured in current clamp. The cell showed only a small decrease in apparent input resistance (sag) with increasing hyperpolarizations. Action potentials were induced by the rebound depolarization at the end of the larger current pulses; these segments are not included for clarity. $B$, Input resistance of the cell shown in $A$ was calculated by plotting the peak membrane voltage response $(\bullet)$ and steady-state membrane voltage response $(\bigcirc)$ versus the injected hyperpolarizing current. The regression line was fitted to the linear portion of the plot obtained with small current pulses. The peak input resistance as determined by the slope of the linear fit was $2.9 \mathrm{G} \Omega$. $C$, Dopaminergic amacrine was held at $-50 \mathrm{mV}$ in voltage clamp and hyperpolarized in $10 \mathrm{mV}$ steps of $2 \mathrm{sec}$ duration to a final voltage of $-100 \mathrm{mV}$. No time-dependent current was seen positive to -90 $\mathrm{mV}$. D, Time-independent resting current was reduced by $1 \mathrm{~mm}$ cesium, and the time-dependent current at -90 and $-100 \mathrm{mV}$ was abolished. Transient current fluctuations were occasionally seen at very negative potentials. $E$, In current clamp, a dopaminergic amacrine had a resting membrane potential of approximately $-45 \mathrm{mV}$ and fired in a rhythmic pattern at a frequency of $5 \mathrm{~Hz}$. Application of $1 \mathrm{~mm}$ cesium for $5 \mathrm{sec}$ had no significant effect on the membrane potential of the cell or its firing frequency. 


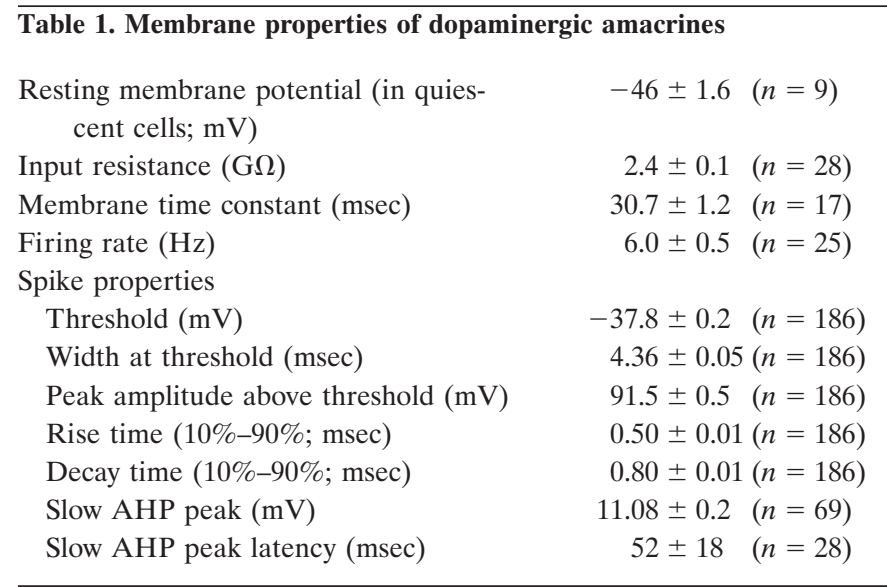

Data represent mean \pm SEM; the number of cells is given in parentheses.

Table 2. Effects of drugs on interspike intervals

\begin{tabular}{lll} 
& Control $(\mathrm{msec})$ & Drug $(\mathrm{msec})$ \\
\hline $\mathrm{CsCl}(1 \mathrm{mM})$ & $162 \pm 5(5)$ & $151 \pm 2(5)$ \\
$\mathrm{CoCl}_{2}(0.5 \mathrm{~mm})$ & $113 \pm 1(4)$ & $102 \pm 1(4)$ \\
Charybdotoxin $(10 \mathrm{nM})$ & $174 \pm 6(5)$ & $159 \pm 4(5)^{*}$ \\
Apamin $(1 \mu \mathrm{M})$ & $169 \pm 3(5)$ & $168 \pm 3(5)$ \\
TEA $(0.5 \mathrm{mM})$ & $162 \pm 5(5)$ & $148 \pm 3(5)^{*}$ \\
TEA $(40 \mathrm{~mm})$ & $139 \pm 3(6)$ & $147 \pm 2(6)$ \\
4-Aminopyridine $(100 \mu \mathrm{M})$ & $144 \pm 4(5)$ & $85 \pm 1(5)^{*}$
\end{tabular}

$\overline{\text { One hundred successive interspike intervals were measured per cell, and the number }}$ of cells is given in parentheses. Data represent mean \pm SEM of pooled measurements.

*Significant differences $(p<0.01, t$ test $)$.

some cells, with occasional misses, and irregular in others. Cells that became quiescent on establishment of whole-cell recording had an average resting potential of $-46 \pm 1.6 \mathrm{mV}(n=9)$, approximately corresponding to the midpoint of the slowly rising ramp that led to spike initiation in spontaneously active cells.

For comparison with identified dopaminergic amacrines, we also recorded from unlabeled large neurons, probably ganglion cells. These had resting membrane potentials of -50 to $-70 \mathrm{mV}$ and were usually silent. On occasion, unlabeled cells with a depolarized membrane potential generated spikes spontaneously, but their pattern of firing was irregular, and they never exhibited the rhythmic activity of dopaminergic amacrines. Dopaminergic amacrine cells also differed markedly from putative ganglion cells in their response to injected current pulses, applied after spontaneous activity was halted by hyperpolarization to -50 to -55 $\mathrm{mV}$ (Fig. 2C). With injection of increasing amounts of depolarizing current, dopaminergic amacrines responded with an increased frequency of firing up to a limit of $22 \pm 2 \mathrm{~Hz}(n=9)$, beyond which they entered depolarizing block. In contrast, putative ganglion cells were able to fire at much higher frequencies (up to $60 \mathrm{~Hz}$ ) without entering depolarizing block. The comparison suggests fundamental differences in the intrinsic membrane properties of the two types of neurons.

\section{$I_{\mathrm{h}}$ is not responsible for spontaneous activity}

The spontaneous activity of dopaminergic amacrines (Fig. 2B) was characterized by relatively broad action potentials (average spike duration $4.36 \pm 0.05 \mathrm{msec} ; n=186$; measured at threshold), triggered at a relatively depolarized threshold $(-37.8 \pm 0.2 \mathrm{mV}$; $n=186)$. Average spike height, measured from threshold to peak, was $91.5 \pm 0.5 \mathrm{mV}(n=186)$. The action potentials were preceded by a slow depolarization and followed by a prominent afterhyperpolarization, which merged into the slow depolarization preceding the next spike.

In many excitable cells that are spontaneously active, the hyperpolarization-activated cation current $I_{\mathrm{h}}$ plays a crucial role (DiFrancesco et al., 1986; McCormick and Pape, 1990; Hille, 1992; Pape, 1996). However, this does not seem to be true for the spontaneous activity of dopaminergic amacrines. Under current clamp, injection of hyperpolarizing pulses showed only a small amount of "sag" of the voltage response (Fig. $3 A, B$ ). The input resistance of dopaminergic amacrines was high, $2.4 \pm 0.1 \mathrm{G} \Omega$ $(n=28)$ measured from the tangent of the $I-V$ curve at the resting membrane potential, and decreased by only $10-15 \%$ with hyperpolarization beyond $-150 \mathrm{mV}$ (Fig. $3 B$ ). This suggests the absence of a significant hyperpolarization-activated conductance. The membrane time constant was $30.7 \pm 1.2 \mathrm{msec}(n=17)$. The membrane properties of dopaminergic amacrines under current clamp are summarized in Table 1.

Voltage-clamp experiments suggested that $I_{\mathrm{h}}$ is present but very small in dopaminergic amacrines. Long ( $2 \mathrm{sec})$ hyperpolarizing voltage steps delivered from a holding potential of $-50 \mathrm{mV}$ elicited only small ( $<15 \mathrm{pA})$ time-dependent currents, even with hyperpolarization to $-100 \mathrm{mV}$ (Fig. 3C). Consistent with $I_{\mathrm{h}}$, the time-dependent current was inhibited by $1 \mathrm{~mm}$ extracellular cesium (Fig. 3D).

We tested for a contribution of $I_{\mathrm{h}}$ to spontaneous firing by application of $1 \mathrm{~mm}$ cesium under current clamp. Cesium had no significant effects on firing frequency, membrane potential, or shape of the action potentials (Fig. $3 E$, Table 2). Thus, although dopaminergic amacrines have a small $I_{\mathrm{h}}$, this current does not contribute to pacemaking. Evidently, the current is insignificant at the voltages (positive to $-60 \mathrm{mV}$ ) reached during spontaneous activity.

\section{Voltage-dependent calcium current}

Important roles have been found for voltage-dependent calcium currents in the spontaneous electrical activity of some types of excitable cells. In particular, the class of calcium channels known as low-threshold, low-voltage-activated, or T-type channels is often associated with cells capable of spontaneous firing, including cardiac sinoatrial cells, neuroendocrine cells, and thalamic neurons (Hagiwara et al., 1988; Bal and McCormick, 1993; Gutnick and Yarom, 1989; Huguenard, 1996). One possible mechanism of rhythmic spontaneous activity is a cycle involving calcium entry through voltage-dependent calcium channels and hyperpolarization resulting from calcium-activated potassium current (Llinás, 1988; Bal and McCormick, 1993).

Current-clamp recordings showed that no type of voltagedependent calcium current was necessary for spontaneous activity. When calcium was completely removed from the extracellular solution (replaced by $0.5 \mathrm{~mm}$ cobalt), the frequency of firing did not change significantly (Fig. $4 A$, Table 2 ), although the amplitude of the action potentials was reduced (to $78.6 \pm 0.6 \mathrm{mV} ; n=$ 18 ; or by $\sim 14 \%$ ).

No evidence was found for T-type calcium channels in dopaminergic amacrines. With ionic conditions to isolate calcium currents, a substantial voltage-activated current was measured, which was abolished by cadmium (Fig. 4B), but there was no component with the low-threshold and rapid inactivation expected from T-type current. These results suggest that voltage- 
A

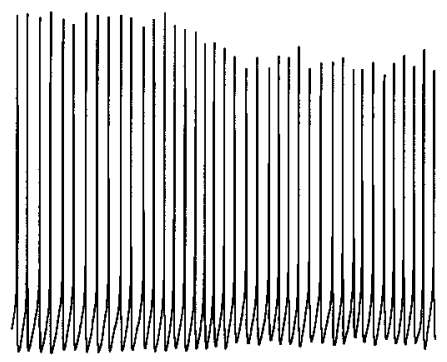

$20 \mathrm{mV}$

$$
0.5 \mathrm{mM} \mathrm{Co}^{2+}
$$

$0.5 \mathrm{~s}$

C

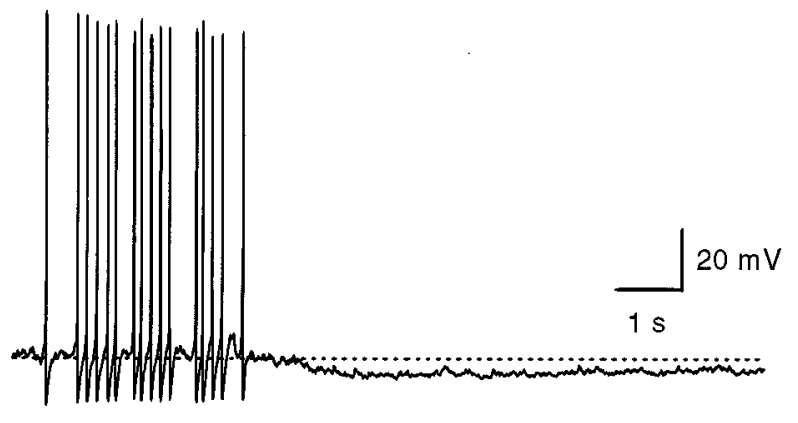

$1 \mu \mathrm{M}$ TTX

D

Control
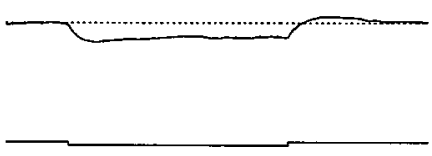

$\mathrm{F}$

$1 \mu \mathrm{M}$ TTX

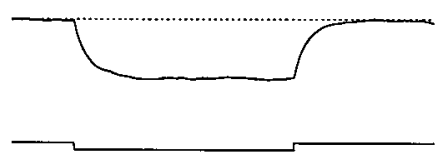

B

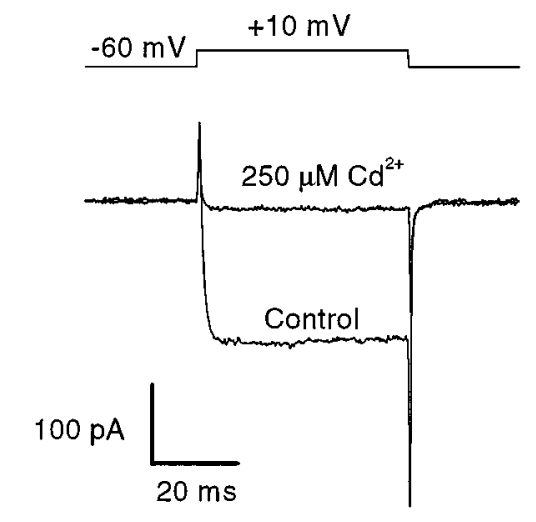

Figure 4. Effects of TTX and cobalt on the spontaneous activity of dopaminergic amacrines. $A$, In current clamp, a dopaminergic amacrine had a resting membrane potential of $-49 \mathrm{mV}$ and fired in a rhythmic pattern at a frequency of $9 \mathrm{~Hz}$. When extracellular calcium was replaced with $0.5 \mathrm{~mm}$ cobalt, the cell depolarized to $-46 \mathrm{mV}$, the amplitude of the action potentials was reduced, but the frequency did not change significantly. Extracellular solution (in mM): 137 $\mathrm{NaCl}, 5.4 \mathrm{KCl}, 2.3 \mathrm{MgCl}_{2}, 0.5 \mathrm{CoCl}_{2}$, and 5 HEPES. $B$, Dopaminergic amacrine was recorded in voltage clamp at a holding potential of $-60 \mathrm{mV}$. A depolarizing voltage step to $10 \mathrm{mV}$ (50 msec duration) induced an inward current flowing through voltageactivated calcium channels. This current was completely abolished by extracellular cadmium $(250 \mu \mathrm{M})$. $C$, In current clamp, a dopaminergic amacrine had a resting membrane potential of $-45 \mathrm{mV}$ and fired in a rhythmic pattern at a frequency of $5 \mathrm{~Hz}$. When TTX $(1 \mu \mathrm{M}, 1 \mathrm{sec})$ was applied extracellularly, the cell became silent and hyperpolarized to $-50 \mathrm{mV}$. After $20 \mathrm{sec}$, the cell resumed firing, although with reduced spike amplitude (data not shown). After complete recovery from TTX, the amplitude of the action potentials gradually increased to predrug levels. $D$, In current clamp, a dopaminergic amacrine was held at $-50 \mathrm{mV}$ to suppress spontaneous discharge. The cell was then further hyperpolarized by injecting a current pulse of $-10 \mathrm{pA}$ for $400 \mathrm{msec}$. At the offset of the current injection, a slow rebound depolarization beyond the holding potential could be observed (note deviation from the dotted line). $E$, Same cell as in $D$. With a larger hyperpolarizing current step $(-20 \mathrm{pA}, 400 \mathrm{msec})$, the rebound depolarization at the offset of the current pulse triggered an action potential. $F$, Same cell and protocol as in $D$. Extracellular application of TTX blocked both the slow depolarization and the action potential at the offset of the current pulse. $G$, Same cell and protocol as in $D$. Addition of cobalt $(250 \mu \mathrm{M})$ to the standard extracellular solution had no effect on the spike discharge at the offset of the current pulse. The larger amplitude of the voltage response was probably caused by an increase in the input resistance of the cell because of block of nonspecific leak conductances. 
A

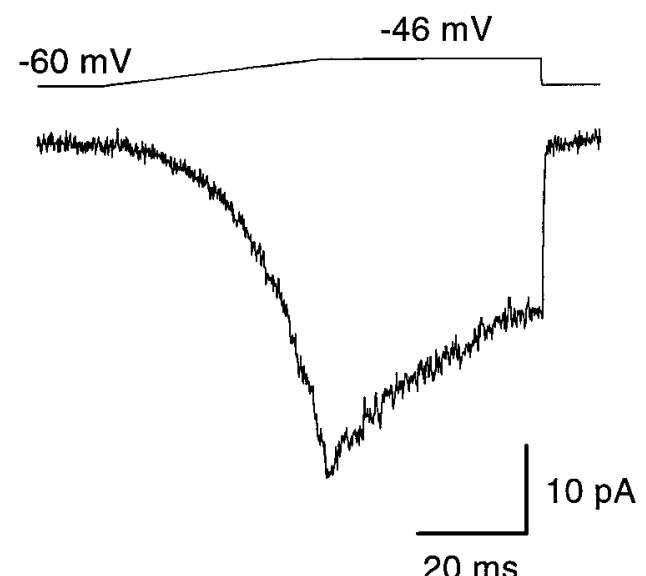

$20 \mathrm{~ms}$
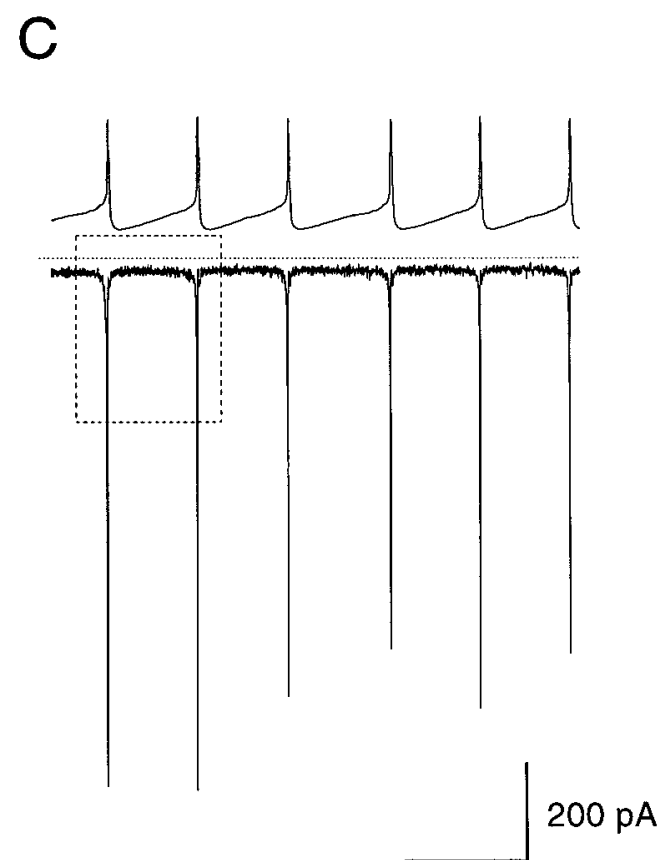

$200 \mathrm{~ms}$

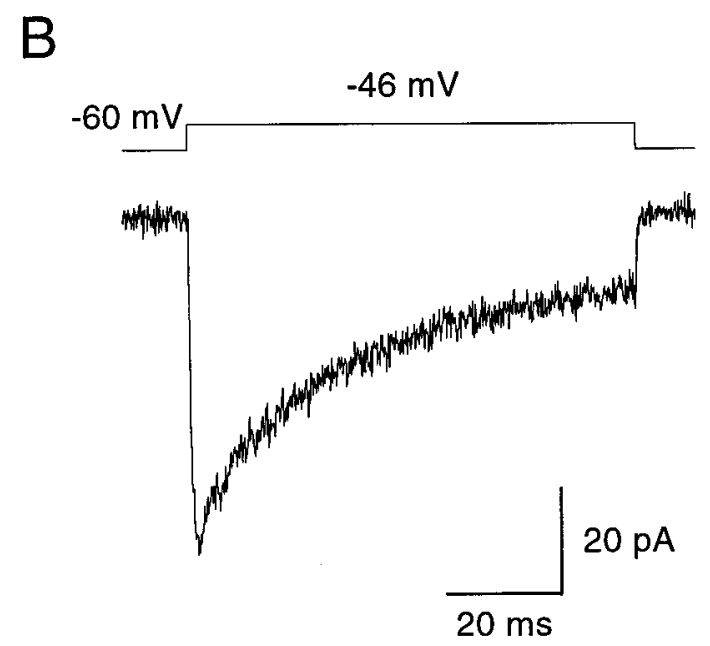

$\mathrm{D}$

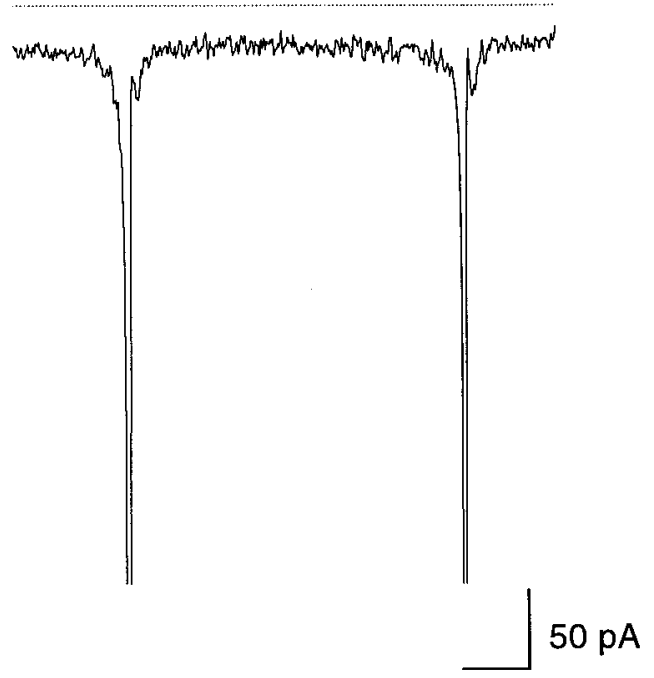

$25 \mathrm{~ms}$

Figure 5. Subthreshold sodium current active between spikes. The current traces of $A-D$ were obtained by subtracting currents recorded in the presence of $1 \mu \mathrm{M}$ TTX from control currents. $A$, Dopaminergic amacrine was ramped from -60 to $-46 \mathrm{mV}$ at the speed of its naturally occurring slow depolarization $\left(350 \mathrm{mV} \mathrm{sec}^{-1}\right)$. The cell membrane was then held at this potential for $40 \mathrm{msec}$ before returning to the holding potential of $-60 \mathrm{mV}$. This stimulus protocol elicited a TTX-sensitive inward sodium current with a peak amplitude of $-36 \mathrm{mV}$ and a steady-state value of $-20 \mathrm{pA}$. $B$, Same cell as in $A$ was recorded in voltage-clamp at a holding potential of $-60 \mathrm{mV}$. A rectangular voltage step to the average resting membrane potential of -46 $\mathrm{mV}(80 \mathrm{msec})$ elicited an inward sodium current with a peak amplitude of $-63 \mathrm{pA}$, which inactivated to a steady-state value of $-15 \mathrm{pA}$. The time course of inactivation could be fitted with a single exponential function $(\tau=23.9 \mathrm{msec})$. $C$, TTX-sensitive sodium current activated by a segment of spontaneous activity used as command stimulus in the voltage-clamp mode. The cell generated a large, fast transient sodium current at spike threshold and a persistent sodium current during the interspike interval (note deviation from dotted line at $0 \mathrm{pA}$ ). The area enclosed in the rectangle is enlarged in $D$.

dependent calcium current contributes to the action potential but is not critically involved in the depolarization that precedes it.

\section{Voltage-dependent sodium current}

Previous experiments showed that the action potentials of dopaminergic amacrines are primarily attributable to tetrodotoxin- sensitive, voltage-dependent sodium channels (Gustincich et al., 1997). Consistent with this finding, reducing sodium from 137 to 50 mм [with substitution by the impermeant cation $N$-methyl-Dglucamine (NMDG)] resulted in smaller, broader spikes, whereas with complete replacement of sodium, the spikes were abolished. In voltage clamp, replacement of sodium by NMDG resulted in 
A

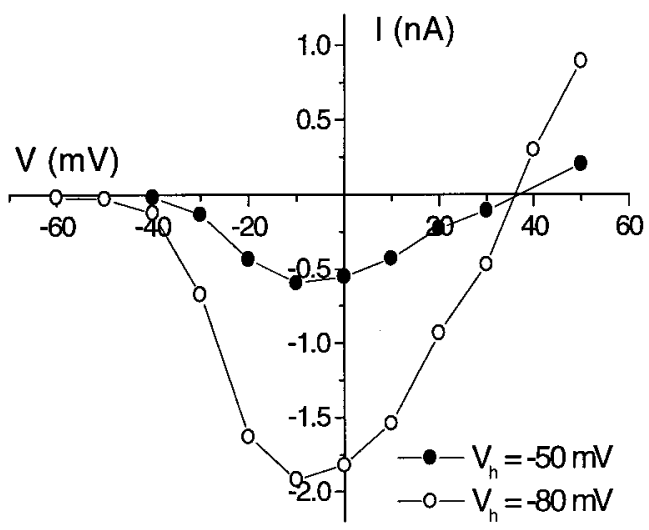

C

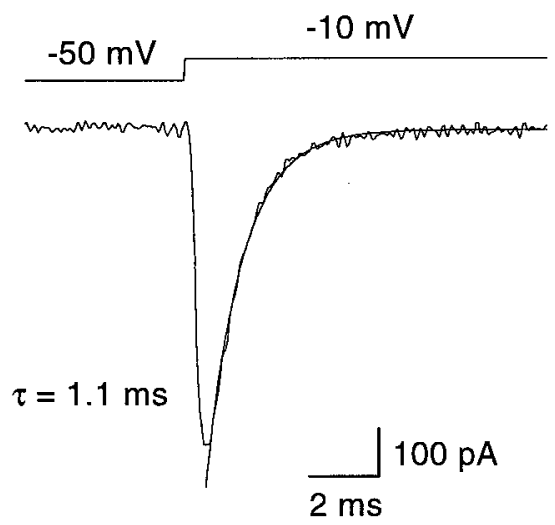

$E$

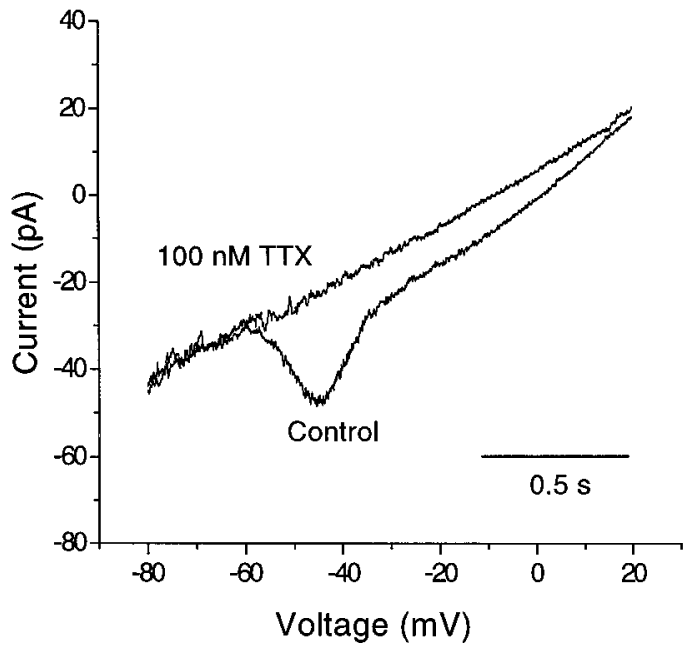

B

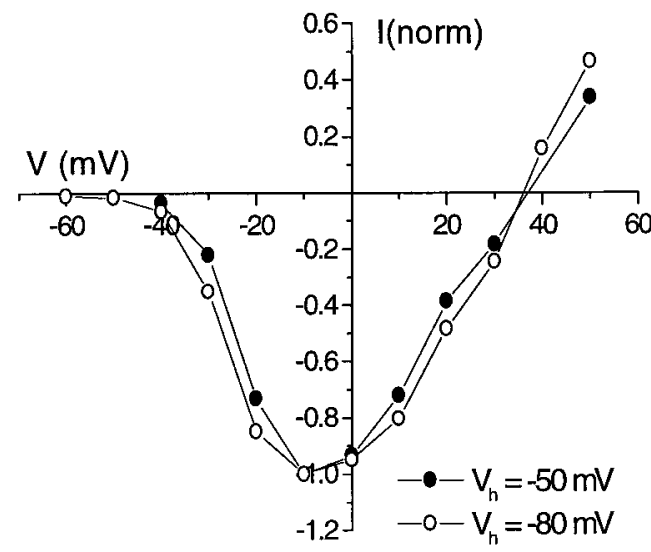

$\mathrm{D}$

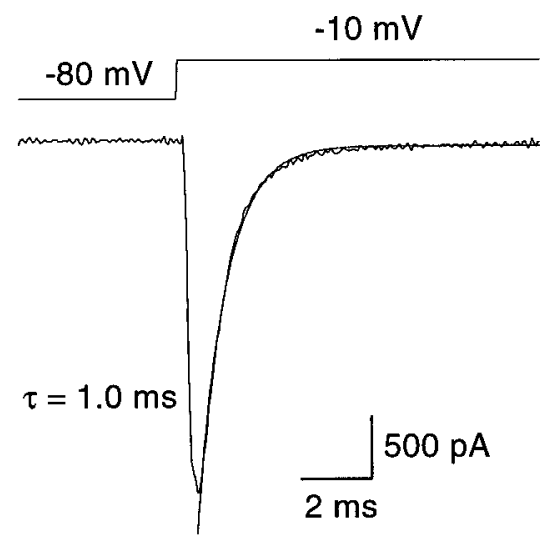

$\mathrm{F}$

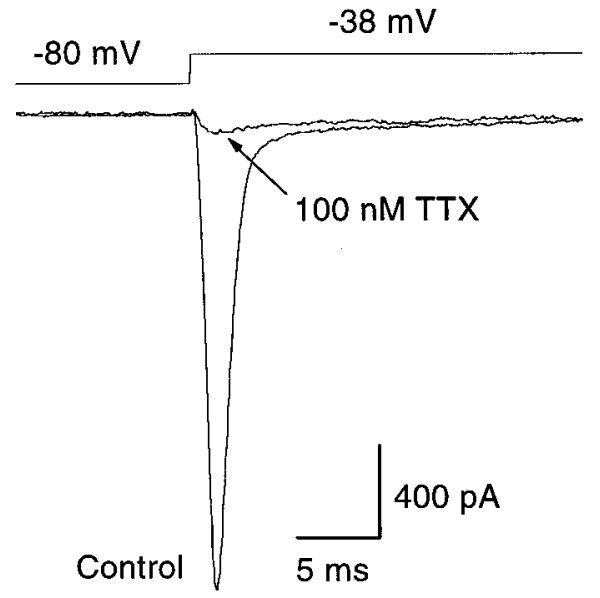

Figure 6. Properties of the subthreshold sodium current. $A$, Current-voltage relation of sodium currents of dopaminergic amacrines elicited from holding potentials of $-80 \mathrm{mV}(\bigcirc)$ or $-50 \mathrm{mV}(\bullet)$. The currents have different amplitudes but similar voltage dependence. $B$, The two $I-V$ curves of $A$ have been normalized to the peak current at $-10 \mathrm{mV}$ and superimposed. $C, D$, Voltage steps to $-10 \mathrm{mV}$ from either -50 or $-80 \mathrm{mV}$. Decay phases are fit with a single exponential function. Average time constants of decay were $1.11 \pm 0.04 \mathrm{msec}(n=5)$ and $0.97 \pm 0.04 \mathrm{msec}(n=5)$, respectively. E, Current evoked by continuously ramping the command potential from -80 to $20 \mathrm{mV}$ at slow speed $(60 \mathrm{mV} \mathrm{sec}-1)$. TTX (10 nM) blocked the sodium current to $0.38 \pm 0.07(n=5)$ of control values (data not shown), whereas $100 \mathrm{~nm}$ TTX reduced the current to $0.12 \pm 0.04(n=5) . F$, When the cell was stepped from -80 to $-38 \mathrm{mV}$ (threshold of action potential generation), a large transient sodium current was elicited. This current showed the same sensitivity to TTX when compared with the current evoked by the slow ramp in $E$. TTX (10 nM) inhibited the current to $0.46 \pm 0.06(n=5)$ and $100 \mathrm{nM}$ TTX to $0.07 \pm 0.01(n=5)$ of control values. 
A
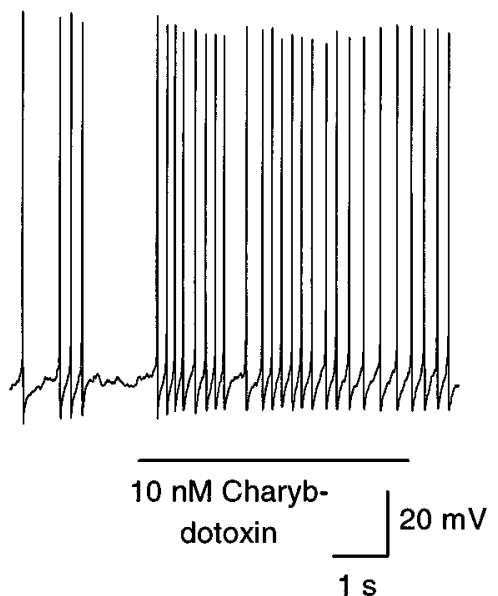

D
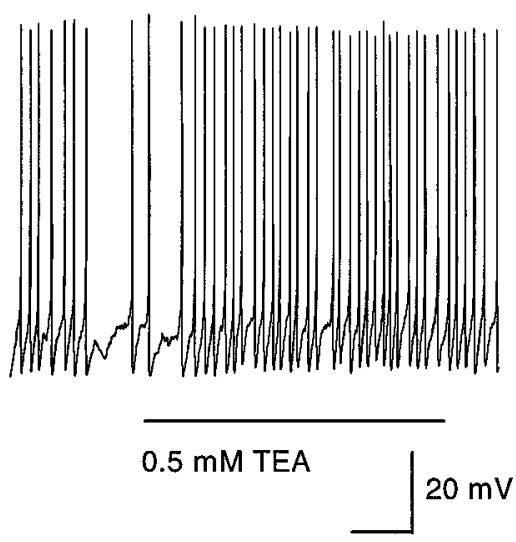

$1 \mathrm{~s}$

$\mathrm{G}$

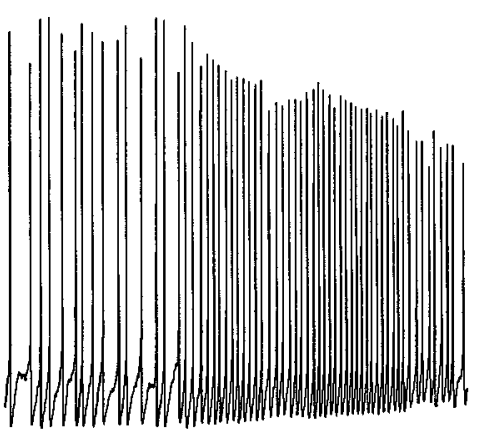

$100 \mu \mathrm{M} 4-\mathrm{AP}$ $20 \mathrm{mV}$
B
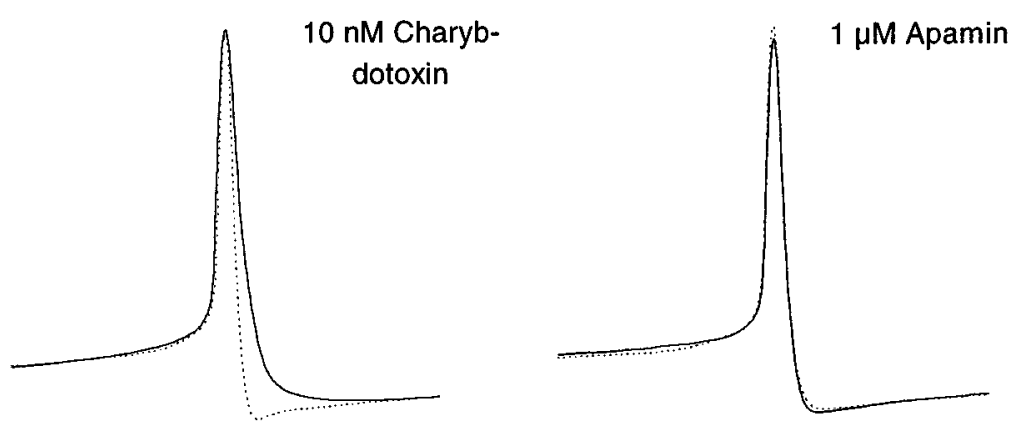

E

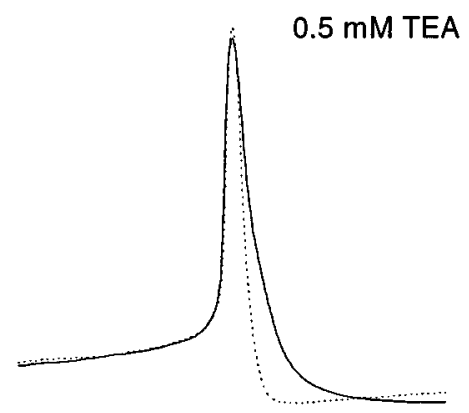

F
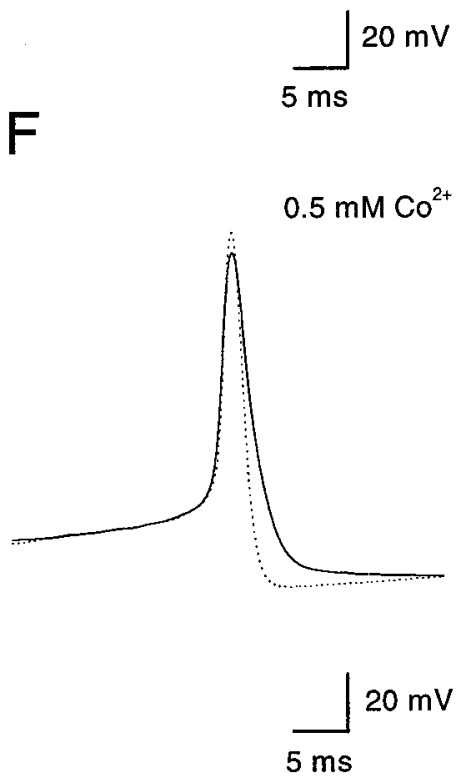

\section{$\mathrm{H}$}

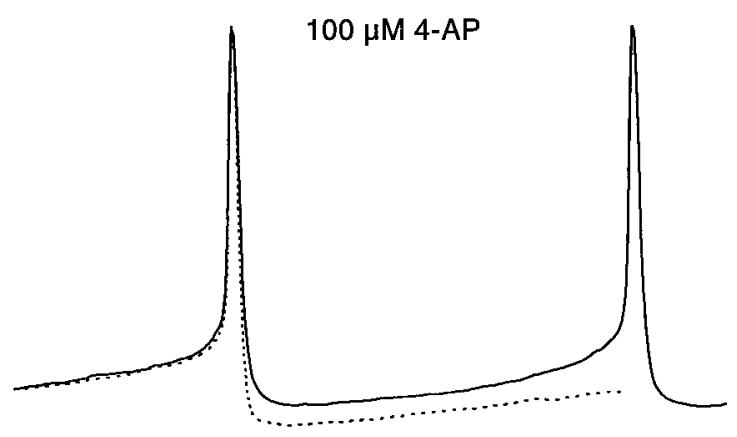

$20 \mathrm{mV}$

$1 \mathrm{~s}$

$25 \mathrm{~ms}$

Figure 7. Effects of blocking BK- and A-type potassium channels on action potentials. $A$, Block of calcium-dependent potassium channels of the BK type by charybdotoxin $(10 \mathrm{nM})$ had no effect on the membrane potential and a modest effect on the firing frequency. $B$, Action potentials were elicited by injecting depolarizing current pulses $(5 \mathrm{pA}, 800 \mathrm{msec})$ in a dopaminergic amacrine hyperpolarized to $-50 \mathrm{mV}$ to remove spontaneous activity. Charybdotoxin $(10 \mathrm{nM})$ selectively abolished the slow afterhyperpolarization and broadened the spike during the repolarization phase (from 4.0 to 5.5 $\mathrm{msec}$, measured at threshold). The dotted line indicates the control trace measured in absence of the drug. $C$, Extracellular application of apamin (1 $\mu \mathrm{M})$ had no effect on the shape of the action potential or on its pattern of discharge (data not shown). $D$, Discharge pattern of a dopaminergic amacrine was scarcely affected by extracellular application of TEA $(0.5 \mathrm{~mm})$. E. Similar to charybdotoxin, TEA ( $0.5 \mathrm{~mm})$ blocked the (Figure legend continues) 
complete disappearance of rapidly inactivating inward currents. The effects of ion substitution were fully reversible in both current clamp and voltage clamp (data not shown).

Application of TTX (1 $\mu \mathrm{M})$ blocked action potentials, as expected (Fig. $4 C$ ). In addition, there was no rhythmic, subthreshold oscillation of the voltage in the presence of TTX, suggesting that both spike generation and the depolarization leading to threshold depend on TTX-sensitive sodium current. Consistent with the presence of substantial depolarizing sodium current between spikes, TTX had the additional effect of hyperpolarizing the cells by $4.8 \pm 0.7 \mathrm{mV}(n=6)$.

The dependence of the spontaneous activity of dopaminergic amacrines on TTX-sensitive sodium channels was also illustrated by an experiment following that done by Grace and Onn (1989) for dopaminergic neurons of the substantia nigra. The spontaneous activity of a dopaminergic amacrine was abolished by holding its membrane potential at $-50 \mathrm{mV}$, and the cell was then further hyperpolarized to $-60 \mathrm{mV}$ by injecting a $-10 \mathrm{pA}$ current pulse of $400 \mathrm{msec}$. At the offset of the current injection, the membrane potential overshot the original holding potential, giving rise to a slow depolarization of $5.6 \pm 0.5 \mathrm{mV}(n=13)$ and $120 \mathrm{msec}$ duration (Fig. 4D). With injection of a larger hyperpolarizing current ( $-20 \mathrm{pA}, 400 \mathrm{msec}$ ), the "rebound" depolarization was enough to trigger a spike (Fig. $4 E$ ). In different types of neurons, such anode break excitation can be attributable to either TTXsensitive sodium current or T-type calcium current. In the dopaminergic amacrines, the rebound depolarization was inhibited completely by TTX (Fig. $4 F$ ) but was unaffected by cobalt (Fig. $4 G)$, suggesting involvement of sodium channels but not calcium channels.

These current-clamp results suggest that TTX-sensitive sodium channels may be crucial for the depolarization leading to threshold as well as for the rapid upstroke of the action potentials. In voltage-clamp experiments, we directly examined sodium currents active at subthreshold voltages. Figure $5 A$ shows the TTXsensitive sodium current elicited by a ramp of voltage from -60 to $-46 \mathrm{mV}$ over $40 \mathrm{msec}$, a voltage protocol that mimics the initial phase of spontaneous depolarization after an action potential. This protocol reliably activated a sodium current, which reached a peak amplitude of $-31 \pm 7 \mathrm{pA}(n=7)$ at the end of the ramp. In a cell with a $2 \mathrm{G} \Omega$ resting resistance, a current this size is very significant. It is striking that although the depolarization from $-60 \mathrm{mV}$ is slow, inactivation of the sodium current must also be slow over this voltage range, because so much current remains noninactivated at the end of the ramp. In fact, comparison with current elicited by a step directly from -60 to $-46 \mathrm{mV}$ (Fig. $5 B$ ) suggested that inactivation during the ramp reduces current by only $\sim 50 \%$.

To directly examine the sodium current active during spontaneous firing, we used a segment of spontaneous activity recorded under current clamp as the voltage command in a voltage-clamp experiment (Fig. 5C,D). The resulting currents were recorded with and without TTX to isolate current carried by TTX-sensitive sodium channels. In addition to the expected large inward current flowing during the upstroke of the action potential, there was a smaller inward current throughout the interspike intervals. This current averaged $-39 \pm 8 \mathrm{pA}(n=13)$ when measured at -46 $\mathrm{mV}$, near the midpoint of the slow depolarization.

These results suggest that TTX-sensitive sodium channels are open at the interspike voltage range of -60 to $-40 \mathrm{mV}$ and play a central role in producing the slow depolarization leading to the next spike. To address the possibility that the sodium channels active in the interspike interval are distinct from those responsible for the upstroke of the action potential, we used voltage protocols designed to test for the existence of multiple types of sodium channels. With the idea that distinct types of channels may have different steady-state inactivation properties, we compared the voltage dependence and kinetics of sodium currents from a steady holding potential of $-50 \mathrm{mV}$, at which $\sim 75 \%$ of the total sodium current is inactivated, with those evoked from -80 $\mathrm{mV}$, at which all sodium current is available. The currents elicited from $-50 \mathrm{mV}$ were reduced to $\sim 25 \%$ of those from $-80 \mathrm{mV}$ but had indistinguishable voltage dependence (Fig. 6A,B). The kinetics of the currents elicited from the two holding potentials were also the same, and inactivation of both currents could be fit well by a single exponential (Fig. $6 C, D$ ), consistent with a single type of channel.

We also compared the TTX sensitivity of the channels giving steady currents in the voltage range of the interspike interval with that of channels activated by conventional step depolarizations from negative holding potentials. With a slow voltage ramp, inward current was elicited at voltages positive to $-60 \mathrm{mV}$ and reached a peak at $-45 \mathrm{mV}$. The TTX sensitivity of the rampevoked current was indistinguishable from that of a current elicited by a step from -80 to $-38 \mathrm{mV}$; in both cases, $10 \mathrm{~nm}$ TTX reduced the current by $\sim 50 \%$ and $100 \mathrm{~nm}$ TTX reduced it by $\sim 90 \%$ (Fig. 6E, F).

Cerebellar Purkinje neurons, which also fire spontaneously even when dissociated and with all synaptic contacts removed (Nam and Hockberger, 1997; Raman and Bean, 1997), have an unusual "resurgent" sodium current active at subthreshold voltages (Raman and Bean, 1997). This is a time-dependent current that follows large depolarizations that have produced maximal inactivation; we found no such current in dopaminergic amacrines using similar protocols.

\section{Potassium currents, afterhyperpolarization, and the interspike interval}

We next examined the dependence of the spontaneous activity on various types of potassium channels. Although the experiments so far suggest that TTX-sensitive sodium current supplies the main depolarizing current between spikes, it is possible that potassium current activated during the action potential is also necessary to maintain spontaneous activity. For example, the hyperpolarization after the action potential (reaching $-60 \mathrm{mV}$ ) might be necessary to remove inactivation of sodium channels. We therefore examined the effects of various blockers of specific

\footnotetext{
afterhyperpolarization and slowed the repolarization phase of the spike (from 3.6 to $5.6 \mathrm{msec}$, measured at threshold). $F$, Cobalt (0.5 mM) had effects on the action potential similar to those of charybdotoxin and low TEA: block of the afterhyperpolarization and broadening of the spike (from 4.2 to 5.7 msec, measured at threshold). In addition, the amplitude of the spike was slightly decreased (from 89 to $81 \mathrm{mV}$ ), probably because of reduced calcium influx in the presence of cobalt. $G$, Extracellular 4-AP $(100 \mu \mathrm{M})$ depolarized a spontaneously firing dopaminergic amacrine. In addition, the firing frequency was increased to $13-14 \mathrm{~Hz}$. $\mathrm{H}$, Same cell as in $\mathrm{G}$. Voltage trajectory of an action potential before (dotted line) and immediately after the onset of application of 4-AP (solid line). The cell was depolarized by 5-6 mV during the interspike interval, whereas the amplitude was not yet affected.
} 
potassium channels on spontaneous activity and action potential waveform.

Two blockers of BK-type, calcium-activated potassium channels, charybdotoxin $(10 \mathrm{nM})$ and a low concentration $(0.5 \mathrm{~mm})$ of tetraethylammonium (TEA), were tested. Their effect on the frequency of spontaneous firing was modest (Fig. $7 A, D$; Table 2), although both changed the form of the action potential by slowing repolarization and reducing the afterhyperpolarization (Fig. $7 B, E)$. Apamin, a blocker of the SK class of calcium-activated potassium channels, had no effect on spontaneous firing (Table 2) and also had no effect on the action potential waveform (Fig. $7 C$ ). Block of calcium entry by $0.5 \mathrm{~mm}$ cobalt, which also did not alter significantly the frequency of spontaneous firing (Fig. 4A), reduced the afterhypolarization in a very similar manner as charybdotoxin and $0.5 \mathrm{~mm}$ TEA (Fig. $7 F$ ). These results suggest that calcium-activated BK channels contribute to the repolarizing phase of the action potential and to the afterhyperpolarization but that the afterhyperpolarization is of little consequence for the frequency of spontaneous firing.

Figure 7, $G$ and $H$, shows the effects of 4-aminopyridine (4AP), a blocker of A- and D-type voltage-activated potassium channels. With application of $100 \mu \mathrm{M}$ 4-AP, the interspike voltage depolarized considerably (Fig. $7 G, H$; on average by $6.7 \pm 1.4 \mathrm{mV}$, $n=6$ ), and the frequency of firing increased (Fig. 7G; Table 2). This suggests that current from A- or D-type channels is present between spikes and normally acts as a brake during the interspike interval. In voltage-clamp experiments, a component of inactivating potassium current was evident on depolarization from a holding potential of $-70 \mathrm{mV}$, consistent with the presence of A-type current in the neurons (data not shown).

To examine possible participation in spontaneous activity of other voltage-activated potassium channels, we examined the effect of a high concentration (40 mM) of TEA, which would be expected to block most types of voltage-activated potassium currents. TEA at $40 \mathrm{~mm}$ caused a substantial depolarization of dopaminergic amacrines and a reduction in amplitude and broadening of the action potentials (Fig. $8 A$ ). Action potentials in the presence of $40 \mathrm{~mm}$ TEA had a prominent plateau, presumably originating from high-threshold calcium current (Fig. 8B). In addition, the afterhyperpolarization was abolished. Despite the dramatic effects of TEA on the action potential shape, there was no significant effect on the frequency of firing (Table 2). Taken together, the effects of blocking potassium channels and calcium channels were remarkable because the frequency of spontaneous firing was scarcely affected even when the interspike voltage and action potential shape changed dramatically. Spontaneous firing appears to be a robust property of this type of neuron.

\section{DISCUSSION}

Our results show that dopaminergic amacrines spontaneously fire action potentials in a rhythmic pattern even in the absence of synaptic inputs. TTX-sensitive sodium channels are essential for the spontaneous activity of the cells, which was little affected by inhibition of calcium channels or $I_{\mathrm{h}}$. The voltage-clamp results show directly that substantial sodium current flows through TTXsensitive channels during the interspike intervals, and this current is sufficient to provide the depolarizing drive leading up to threshold during each cycle of firing.

The ability to fire spontaneously at a regular rate is a property that dopaminergic amacrines share with mesencephalic dopaminergic neurons (Grace and Bunney, 1983a,b, 1984; Grace and Onn, 1989; Lacey et al., 1989; Yung et al., 1991), but profound

\section{A}

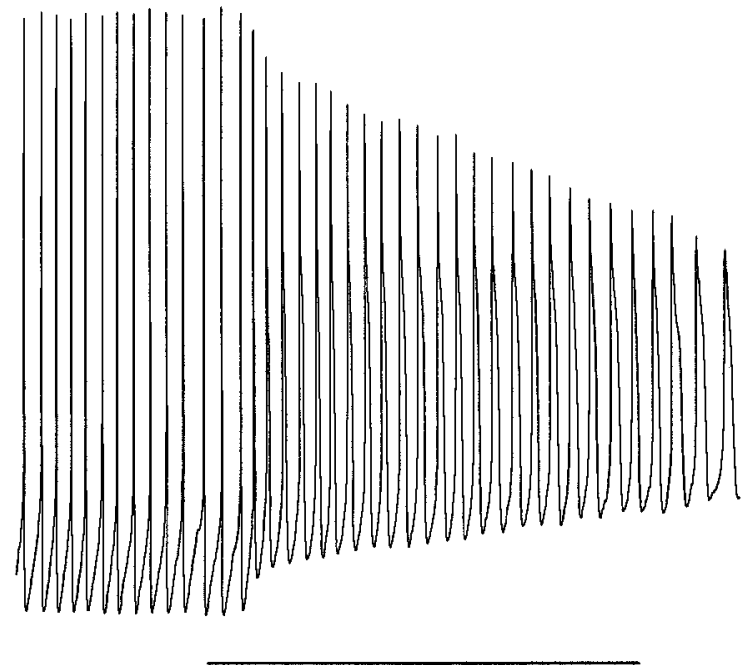

$40 \mathrm{mM}$ TEA

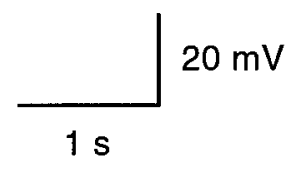

B

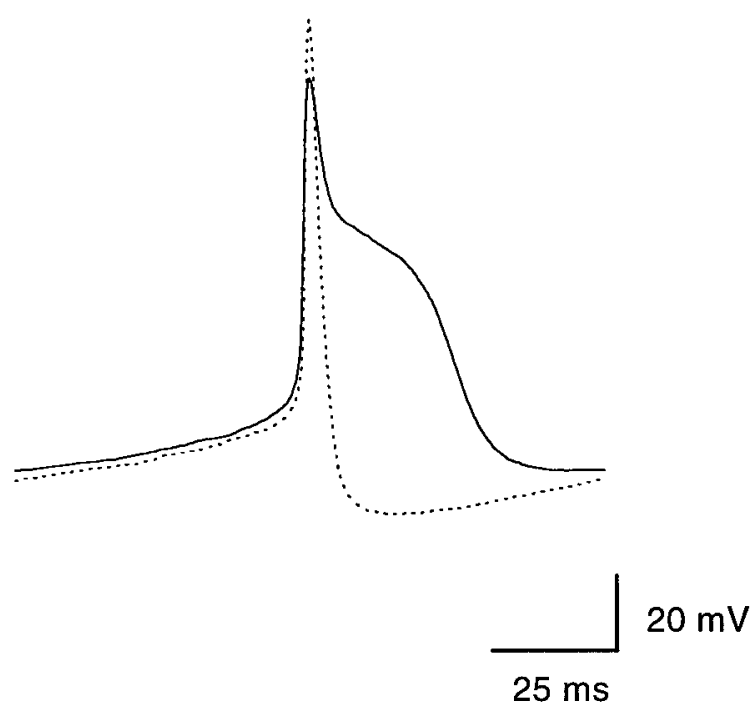

Figure 8. Effects of a high concentration of TEA. $A$, In current clamp, a dopaminergic amacrine had a resting membrane potential of $-48 \mathrm{mV}$ and spontaneously generated action potentials at a frequency of $9 \mathrm{~Hz}$. On extracellular application of TEA $(40 \mathrm{mM}, 3 \mathrm{sec})$, the membrane potential was depolarized by $15-20 \mathrm{mV}$, but the frequency of firing did not change. Extracellular solution (in $\mathrm{mM}$ ): $97 \mathrm{NaCl}, 40 \mathrm{TEACl}, 5.4 \mathrm{KCl}, 1.8 \mathrm{CaCl}_{2}$, $1 \mathrm{MgCl}_{2}, 5 \mathrm{HEPES}$, and 10 glucose. $B$, Same cell as in $A$. Voltage trajectory of an action potential immediately after the onset of TEA application. The membrane potential was slightly depolarized with respect to control (dotted line). The spike amplitude was reduced by $15 \mathrm{mV}$, and the repolarization phase was broadened.

differences exist between the two cell types both in geometry and in the ionic conductances responsible for their activity. Substantia nigra neurons are large projection neurons with a long axon originating from a primary dendrite, and they generate an initial segment sodium spike, followed by a somatodendritic, high- 
threshold calcium spike (Grace and Bunney, 1983b; Llinás et al., 1984; Kita et al., 1986; Häusser et al., 1995). Although dopaminergic amacrines do possess axons in some mammals (Dacey, 1990), it is unclear whether this is the case in the mouse. Furthermore, both rhythmic activity and shape of the action potentials were the same irrespective of whether processes survived the dissociation procedure.

The frequency of firing, shape of action potentials, and voltage range of the subthreshold depolarization are remarkably similar between retinal and midbrain dopaminergic neurons. Furthermore, in both cases a subthreshold, TTX-sensitive sodium current appears to be important for pacemaking (Grace and Onn, 1989). However, in the midbrain neurons, voltage-dependent calcium current seems to play a crucial role (Kita et al., 1986; Fujimura and Matsuda, 1989; Grace and Onn, 1989; Kang and Kitai, 1993; Nedergaard et al., 1993; Yung et al., 1991; Mercuri et al., 1994). In contrast, blocking calcium current had minimal effect on the firing of dopaminergic amacrines. In addition, $I_{\mathrm{h}}$ was very small and did not participate in pacemaking, whereas a prominent $I_{\mathrm{h}}$ current is present in substantia nigra neurons (Harris and Constanti, 1995; Mercuri et al., 1995). In the midbrain neurons, firing rates depend on calcium-activated potassium currents (Harris et al., 1989; Shepard and Bunney, 1991; Ping and Shepard, 1996), whereas in dopaminergic amacrines, blocking such currents had but a modest effect on firing frequency.

The mechanism of pacemaking in dopaminergic amacrines is reminiscent of other cases of oscillatory behavior depending on a subthreshold sodium current (Alonso and Llinás, 1989; Klink and Alonso, 1993; Amitai, 1994; Uteshev et al., 1995) and most closely resembles that of neurons of the suprachiasmatic nucleus, in which spontaneous activity also depends on a sodium current but not $I_{\mathrm{h}}$ or calcium currents (Pennartz et al., 1997). For most neurons, it is uncertain whether subthreshold sodium currents are carried by different channels than those responsible for the upstroke of the action potential (Crill, 1996). In dopaminergic amacrines, we found no evidence that the sodium current in the interspike interval arises from a distinct type of sodium channel. This is in contrast to neurons from the suprachiasmatic nucleus, in which the sodium channels involved in pacemaking appear to differ in kinetics and voltage dependence from those mediating the action potential, and in which the total sodium current inactivates with two distinguishable components (Pennartz et al., 1997).

If the subthreshold current in dopaminergic amacrines arises from the same channels as conventional transient currents, it may represent either a particular mode of gating of the channels (Alzheimer et al., 1993; Brown et al., 1994) or, instead, simply reflect a dynamic equilibrium between closed, open, and inactivated states at voltages in the range of the interspike interval, -60 to $-40 \mathrm{mV}$. At this point, it is impossible to ascribe the sodium current in the interspike interval to a particular sequence of transitions between gating states. The Hodgkin and Huxley model of sodium channel gating is not adequate to describe real channels (Hille, 1992), and its deficiencies may be greatest at subthreshold voltages, at which both activation and inactivation are incomplete. Subthreshold sodium currents may be an intrinsic consequence of the molecular gating mechanism of all sodium channels, in which case they may be common to all neurons. If so, the distinguishing feature of a pacemaking neuron may be lack of a large competing potassium conductance at relevant voltages rather than possession of specialized sodium channels.

The relative invariance of the frequency of firing with many pharmacological interventions, including cesium, cobalt, TEA, and charybdotoxin, seems surprising. The slow interspike depolarization must result from a very small net inward current, and the input resistance of the cell is high. One might expect the system would be sensitive to small changes in the balance of underlying currents, but the experiments show little evidence for this. The reasons for the robustness of the firing frequency in the face of changes in calcium and potassium currents remain to be determined. One possibility is that the decay of the potassium current indirectly causes a compensatory reduction in sodium current by decreasing the afterhypolarization and thereby diminishing or slowing recovery from inactivation of the sodium channels.

Application of 4-AP did lead to increased frequency of firing. According to the analysis of Connor and Stevens (1971a,b), the rate of inactivation of A-type potassium current, which is often sensitive to block by 4-AP, regulates interspike intervals, with inactivation being removed immediately after the action potential and then slowly redeveloping during the interspike depolarization. Consistent with its behavior in Anisodoris neurons (Connor and Stevens, 1971a,b), A-type current contributed only minimally to the repolarizing phase of the action potential, which was little affected by 4-AP.

It seems possible that dopaminergic amacrines also fire spontaneous action potentials in vivo. If their input resistance in the intact retina is similar to that of other large amacrine cells (150 $\mathrm{M} \Omega$ in starburst amacrines; Taylor and Wässle, 1995), a persistent sodium current of the same magnitude as that observed in vitro would depolarize the cell by $\sim 6 \mathrm{mV}$ and, thus, be sufficient to raise the membrane potential to the threshold for generation of an action potential. The presence of a spike-generating neuron in the pathway leading to dopamine release was suggested by Piccolino et al. (1987) on the basis of the effects of veratridine and TTX on the coupling of horizontal cells in the turtle. In vivo, however, the firing pattern of dopaminergic amacrines is probably different from that observed in vitro after removal of all synaptic influences: we have recently shown that the spontaneous activity of isolated dopaminergic amacrines can be abolished by the amacrine cell transmitters GABA and glycine and is stimulated by kainate, an agonist at the receptor for the bipolar cell transmitter glutamate (Gustincich et al., 1997). On this basis, it seems likely that on cessation of illumination the spontaneous discharge of dopaminergic amacrines is inhibited by GABAergic amacrines that receive their input from off-bipolars. It must be emphasized, however, that the cells may not be totally silent in the darkadapted retina; perhaps, a slow rhythmic discharge of action potentials may be responsible for the basal efflux of dopamine that has been reported in the dark (Witkovsky and Dearry, 1991; Djamgoz and Wagner, 1992). Dopaminergic amacrines are probably inhibited in scotopic illumination because of the influence of the glycinergic AII amacrine cells and may fire bursts of action potentials with photopic stimulation as a result of the excitation received from on-bipolars. Such a behavior would cause variations in dopamine release that are consistent with the modulation of coupling between AII amacrines in different conditions of illumination (Bloomfield et al., 1997).

The spread of action potentials throughout the plexus of dopaminergic amacrine cell dendrites in the scleral region of the inner plexiform layer is probably responsible for the depolarization that causes calcium-dependent dopamine release in the light (Sarthy et al., 1981; Boatright et al., 1989; Kolbinger and Weiler, 1993). It is unclear, however, whether dopamine release exclu- 
sively occurs at the synaptic junctions established by dopaminergic amacrines with other amacrine cells. This problem is further complicated by the fact that GABA is colocalized in dopaminergic amacrines (Wässle and Chun, 1988): perhaps GABA is released at the synapses and mediates fast inhibitory events, whereas the release of dopamine takes place throughout the surface of their dendritic tree.

It seems significant that both retinal dopaminergic amacrines and the mesencephalic dopaminergic neurons exhibit pacemaker activity in vitro: this common behavior is even more remarkable considering that different constellations of voltage-gated ion channels apparently converge to generate the same functional phenotype. The spontaneous activity is probably related to a common pattern of ongoing dopamine release. It is interesting, in this respect, that substantia nigra neurons, like dopaminergic amacrines, release dopamine from their dendrites (Geffen et al., 1976; Korf et al., 1976; Cheramy et al., 1981; Lacey et al., 1990; Johnson and North, 1992; Rice et al., 1994). Perhaps the generation of action potentials on removal of inhibitory influences and the resulting depolarization are essential to cause a tonic release of dopamine from the dendritic tree and, thus, ensure a high concentration of the modulator in the intercellular spaces. Then, the released molecules diffuse throughout the retina to influence the activity of more distant targets, such as horizontal cells and photoreceptors.

\section{REFERENCES}

Alonso A, Llinás RR (1989) Subthreshold $\mathrm{Na}^{+}$-dependent theta-like rhythmicity in stellate cells of entorhinal cortex layer II. Nature 342:175-177.

Alzheimer C, Schwindt PC, Crill WE (1993) Modal gating of $\mathrm{Na}^{+}$ channels as a mechanism of persistent $\mathrm{Na}^{+}$current in pyramidal neurons from rat and cat sensorimotor cortex. J Neurosci 13:660-673.

Amitai Y (1994) Membrane potential oscillations underlying firing patterns in neocortical neurons. Neuroscience 63:151-161.

Bal T, McCormick DA (1993) Mechanisms of oscillatory activity in guinea-pig nucleus reticularis thalami in vitro: a mammalian pacemaker. J Physiol (Lond) 468:669-691.

Banerjee SA, Hoppe P, Brilliant M, Chikaraishi DM (1992) 5' flanking sequences of the rat tyrosine hydroxylase gene target accurate tissuespecific, developmental, and transsynaptic expression in transgenic mice. J Neurosci 12:4460-4467.

Bloomfield SA, Xin D, Osborne T (1997) Light-induced modulation of coupling between AII amacrine cells in the rabbit retina. Vis Neurosci 14:565-576.

Boatright JH, Hoel MJ, Iuvone PM (1989) Stimulation of endogenous dopamine release and metabolism in amphibian retina by light- and $\mathrm{K}^{+}$-evoked depolarization. Brain Res 482:164-168.

Brown AM, Schwindt PC, Crill WE (1994) Different voltage dependence of transient and persistent $\mathrm{Na}^{+}$currents is compatible with modal-gating hypothesis for sodium channels. J Neurophysiol 71:2562-2565.

Cardozo DL (1993) Midbrain dopaminergic neurons from postnatal rat in long-term primary culture. Neuroscience 56:409-421.

Cardozo DL, Bean BP (1995) Voltage-dependent calcium channels in rat midbrain dopamine neurons: modulation by dopamine and $\mathrm{GABA}_{\mathrm{B}}$ receptors. J Neurophysiol 74:1137-1148.

Cheramy A, Leviel V, Glowinski J (1981) Dendritic release of dopamine in the substantia nigra. Nature 289:537-542.

Connor JA, Stevens CF (1971a) Voltage clamp studies of a transient outward membrane current in gastropod neural somata. J Physiol (Lond) 213:21-30.

Connor JA, Stevens CF (1971b) Prediction of repetitive firing behaviour from voltage clamp data on an isolated neurone soma. J Physiol (Lond) 213:31-53.

Crill WE (1996) Persistent sodium current in mammalian central neurons. Annu Rev Physiol 58:349-362.

Dacey DM (1990) The dopaminergic amacrine cell. J Comp Neurol 301:461-489.
De Waele P, De Groote G, Van de Voorde A, Fiers W, Franssen JD, Herion P, Urbain J (1982) Isolation and identification of monoclonal antibodies directed against human placental alkaline phosphatase. Arch Int Physiol Biochim 90:B21.

DiFrancesco D, Ferroni A, Mazzanti M, Tromba C (1986) Properties of the hyperpolarizing-activated current $\left(i_{\mathrm{f}}\right)$ in cells isolated from the rabbit sino-atrial node. J Physiol (Lond) 377:61-88.

Djamgoz MB, Wagner HJ (1992) Localization and function of dopamine in the adult vertebrate retina. Neurochem Int 20:139-191.

Fujimura K, Matsuda Y (1989) Autogenous oscillatory potentials in neurons of the guinea pig substantia nigra pars compacta in vitro. Neurosci Lett 104:53-57.

Geffen LB, Jessell TM, Cuello AC, Iversen LL (1976) Release of dopamine from dendrites in rat substantia nigra. Nature 260:258-260.

Grace AA, Bunney BS (1983a) Intracellular and extracellular electrophysiology of nigral dopaminergic neurons-1. Identification and characterization. Neuroscience 10:301-315.

Grace AA, Bunney BS (1983b) Intracellular and extracellular electrophysiology of nigral dopaminergic neurons-2. Action potential generating mechanisms and morphological correlates. Neuroscience 10:317-331.

Grace AA, Bunney, BS (1984) The control of firing pattern in nigral dopamine neurons: single spike firing. J Neurosci 4:2866-2876.

Grace AA, Onn SP (1989) Morphology and electrophysiological properties of immunocytochemically identified rat dopamine neurons recorded in vitro. J Neurosci 9:3463-3481.

Gustincich S, Feigenspan A, Wu DK, Koopman LJ, Raviola E (1997) Control of dopamine release in the retina: a transgenic approach to neural networks. Neuron 18:723-736.

Gutnick MJ, Yarom Y (1989) Low threshold calcium spikes, intrinsic neuronal oscillation and rhythm generation in the CNS. J Neurosci Methods 28:93-99.

Hagiwara N, Irisawa H, Kameyama M (1988) Contribution of two types of calcium currents to the pacemaker potentials of rabbit sino-atrial nodal cells. J Physiol (Lond) 395:233-253.

Hainsworth AH, Roper J, Kapoor R, Ashcroft FM (1991) Identification and electrophysiology of isolated pars compacta neurons from guineapig substantia nigra. Neuroscience 43:81-93.

Harris NC, Constanti A (1995) Mechanism of block by ZD 7288 of the hyperpolarization-activated inward rectifying current in guinea pig substantia nigra neurons in vitro. J Neurophysiol 74:2366-2378.

Harris NC, Webb C, Greenfield SA (1989) A possible pacemaker mechanism in pars compacta neurons of the guinea-pig substantia nigra revealed by various ion channel blocking agents. Neuroscience 31:355-362.

Häusser M, Stuart G, Racca C, Sakmann B (1995) Axonal initiation and active dendritic propagation of action potentials in substantia nigra neurons. Neuron 15:637-647.

Hikosaka O, Wurtz RH (1983) Visual and oculomotor functions of monkey substantia nigra pars reticulata. III. Memory-contingent visual and saccade responses. J Neurophysiol 49:1268-1284.

Hille B (1992) Ionic channels of excitable membranes. Sunderland, MA: Sinauer.

Huguenard JR (1996) Low-threshold calcium currents in central nervous system neurons. Annu Rev Physiol 58:329-348.

Johnson SW, North RA (1992) Two types of neurone in the rat ventral tegmental area and their synaptic inputs. J Physiol (Lond) 450:455-468.

Kam W, Clauser E, Kim YS, Kan YW, Rutter WJ (1985) Cloning, sequencing, and chromosomal localization of human term placental alkaline phosphatase cDNA. Proc Natl Acad Sci USA 82:8715-8719.

Kang Y, Kitai ST (1993) Calcium spike underlying rhythmic firing in dopaminergic neurons of the rat substantia nigra. Neurosci Res 18:195-207.

Kita T, Kita H, Kitai ST (1986) Electrical membrane properties of rat substantia nigra compacta neurons in an in vitro slice preparation. Brain Res 372:21-30.

Klink R, Alonso A (1993) Ionic mechanisms for the subthreshold oscillations and differential electroresponsiveness of medial entorhinal cortex layer II neurons. J Neurophysiol 70:144-157.

Kolbinger W, Weiler R (1993) Modulation of endogenous dopamine release in the turtle retina: effects of light, calcium, and neurotransmitters. Vis Neurosci 10:1035-1041.

Korf J, Zieleman M, Westerink BHC (1976) Dopamine release in substantia nigra? Nature 260: 257-258.

Lacey MG, Mercuri NB, North RA (1989) Two cell types in rat sub- 
stantia nigra zona compacta distinguished by membrane properties and the actions of dopamine and opioids. J Neurosci 9:1233-1241.

Lacey MG, Mercuri NB, North RA (1990) Actions of cocaine on rat dopaminergic neurones in vitro. Br J Pharmacol 99:731-735.

Le Moal M, Simon H (1991) Mesocorticolimbic dopaminergic network: functional and regulatory roles. Physiol Rev 71:155-234.

Llinás R (1988) The intrinsic electrophysiological properties of mammalian neurons: Insights into central nervous system function. Science 242:1654-1664.

Llinás R, Greenfield SA, Jahnsen H (1984) Electrophysiology of pars compacta cells in the in vitro substantia nigra-a possible mechanism for dendritic release. Brain Res 294:127-132.

Mariani AP, Hokoc JN (1988) Two types of tyrosine hydroxylase immunoreactive amacrine cell in the rhesus monkey retina. J Comp Neurol 276:81-91.

McCormick DA, Pape H-C (1990) Properties of a hyperpolarizationactivated cation current and its role in rhythmic oscillation in thalamic relay neurones. J Physiol (Lond) 431:291-318.

Mercuri NB, Bonci A, Calabresi P, Stratta F, Stefani A, Bernardi G (1994) Effects of dihydropyridine calcium antagonists on rat midbrain dopaminergic neurones. Br J Pharmacol 113:831-838.

Mercuri NB, Bonci A, Calabresi P, Stefani A, Bernardi G (1995) Properties of the hyperpolarization-activated cation current $I_{h}$ in rat midbrain dopaminergic neurons. Eur J Neurosci 7:462-469.

Nam SC, Hockberger PE (1997) Analysis of spontaneous electrical activity in cerebellar Purkinje cells acutely isolated from postnatal rats. J Neurobiol 33:18-32.

Nedergaard S, Flatman JA, Engberg I (1993) Nifedipine- and omegaconotoxin-sensitive $\mathrm{Ca}^{2+}$ conductances in guinea-pig substantia nigra pars compacta neurones. J Physiol (Lond) 466:727-747.

Nguyen-Legros J (1988) Morphology and distribution of catecholamineneurons in mammalian retina. Prog Retinal Res 7:113-147.

Pape H-C (1996) Queer current and pacemaker: the hyperpolarizationactivated cation current in neurons. Annu Rev Physiol 58:299-327.

Pennartz CMA, Bierlagh MA, Geursten AMS (1997) Cellular mechanisms underlying spontaneous firing in rat suprachiasmatic nucleus: involvement of a slowly inactivating component of sodium current. J Neurophysiol 78:1811-1825.

Piccolino M, Witkovsky P, Trimarchi C (1987) Dopaminergic mechanisms underlying the reduction of electrical coupling between horizon- tal cells of the turtle retina induced by D-amphetamine, bicuculline, and veratridine. J Neurosci 7:2273-2284.

Ping HX, Shepard PD (1996) Apamin-sensitive Ca(2+)-activated $\mathrm{K}^{+}$ channels regulate pacemaker activity in nigral dopamine neurons. NeuroReport 7:809-814.

Raman IM, Bean BP (1997) Resurgent sodium current and action potential formation in dissociated cerebellar Purkinje neurons. J Neurosci 17:4517-4526.

Rice ME, Richards CD, Nedergaard S, Hounsgaard J, Nicholson C, Greenfield SA (1994) Direct monitoring of dopamine and 5-HT release in substantia nigra and ventral tegmental area in vitro. Exp Brain Res 100:395-406.

Sarthy PV, Rayborn ME, Hollyfield JG, Lam DMK (1981) The emergence, localization, maturation of neurotransmitter systems during development of the retina in Xenopus laevis. III. Dopamine. J Comp Neurol 195:595-602.

Shepard PD, Bunney BS (1991) Repetitive firing properties of putative dopamine-containing neurons in vitro: regulation by an apaminsensitive $\mathrm{Ca}(2+)$-activated $\mathrm{K}^{+}$conductance. Exp Brain Res 86:141-150.

Tauchi M, Madigan NK, Masland RH (1990) Shapes and distributions of the catecholamine-accumulating neurons in the rabbit retina. J Comp Neurol 293:178-189.

Taylor WR, Wässle H (1995) Receptive field properties of starburst cholinergic amacrine cells in the rabbit retina. Eur $\mathrm{J}$ Neurosci 7:2308-2321.

Uteshev V, Stevens DR, Haas HL (1995) A persistent sodium current in acutely isolated histaminergic neurons from rat hypothalamus. Neuroscience 66:143-149.

Versaux-Botteri C, Nguyen-Legros J, Vigny A, Raoux N (1984) Morphology, density and distribution of tyrosine hydroxylase-like immunoreactive cells in the retina of mice. Brain Res 301:192-197.

Wässle H, Chun MH (1988) Dopaminergic and indoleamineaccumulating amacrine cells express GABA-like immunoreactivity in the cat retina. J Neurosci 8:3383-3394.

Witkovsky P, Dearry A (1991) Functional roles of dopamine in the vertebrate retina. Prog Retinal Res 11:247-292.

Yung WH, Häusser MA, Jack JJB (1991) Electrophysiology of dopaminergic and non-dopaminergic neurones of the guinea-pig substantia nigra pars compacta in vitro. J Physiol (Lond) 436:643-667. 